\title{
Creep-Fatigue Behavior of Alloy 617 at 850 and $950^{\circ} \mathrm{C}$
}

\author{
L. Carroll \\ M. Carroll
}

April 2013

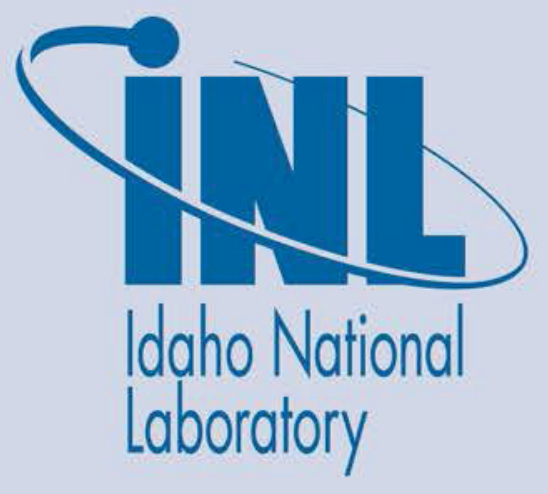

The INL is a U.S. Department of Energy National Laboratory operated by Battelle Energy Alliance 


\section{DISCLAIMER}

This information was prepared as an account of work sponsored by an agency of the U.S. Government. Neither the U.S. Government nor any agency thereof, nor any of their employees, makes any warranty, expressed or implied, or assumes any legal liability or responsibility for the accuracy, completeness, or usefulness, of any information, apparatus, product, or process disclosed, or represents that its use would not infringe privately owned rights. References herein to any specific commercial product, process, or service by trade name, trade mark, manufacturer, or otherwise, does not necessarily constitute or imply its endorsement, recommendation, or favoring by the U.S. Government or any agency thereof. The views and opinions of authors expressed herein do not necessarily state or reflect those of the U.S. Government or any agency thereof. 


\section{Creep-Fatigue Behavior of Alloy 617 at 850 and $950^{\circ} \mathrm{C}$}

L. Carroll and M. Carroll

April 2013

Idaho National Laboratory Idaho Falls, Idaho 83415

http://www.inl.gov

Prepared for the

U.S. Department of Energy

Office of Nuclear Energy

Under DOE Idaho Operations Office

Contract DE-AC07-05ID14517 


\title{
Creep-Fatigue Behavior of Alloy 617 at 850 and $950^{\circ} \mathrm{C}$
}

\author{
INL/EXT-13-28886 \\ Revision 0
}

April 2013

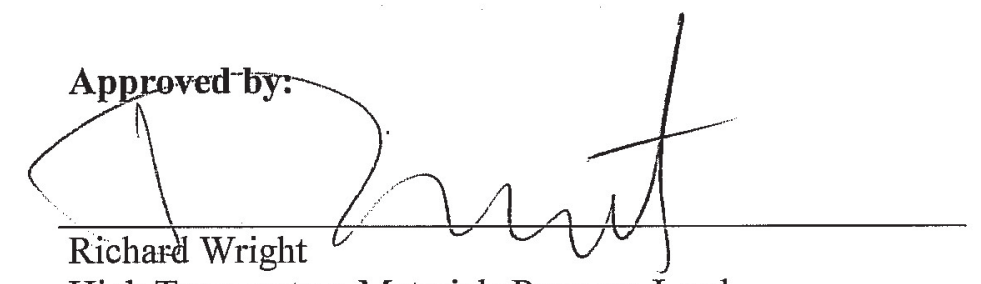

High Temperature Materials Program Lead

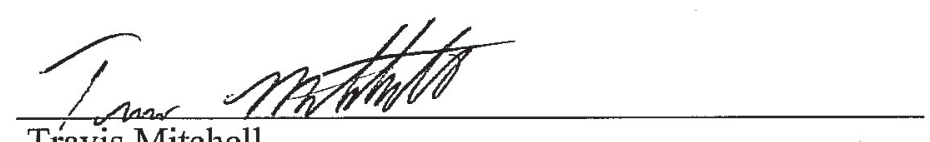

Tŕavis Mitchell

Project Manager VHTR Technology Development Office
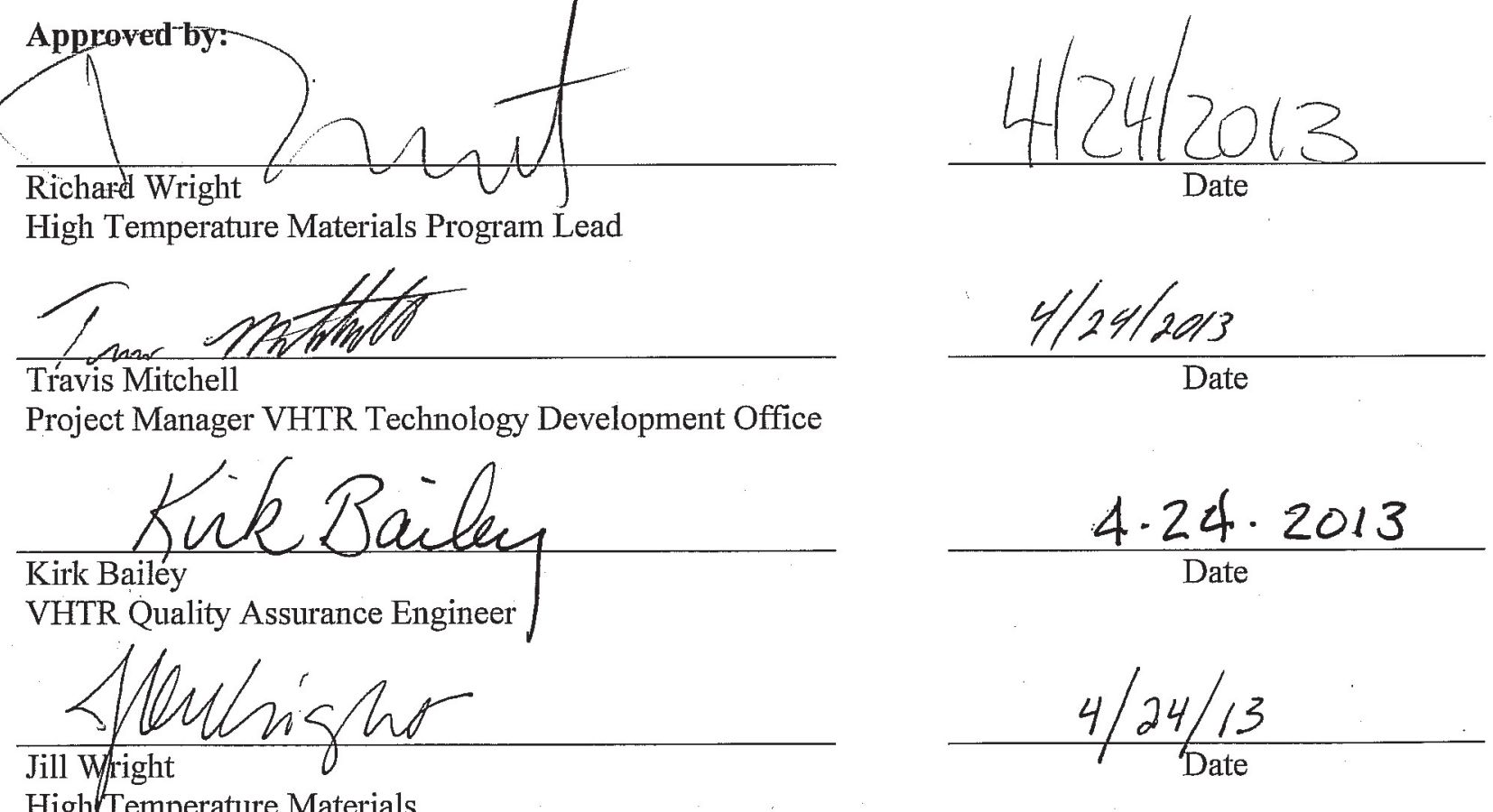

High Temperature Materials

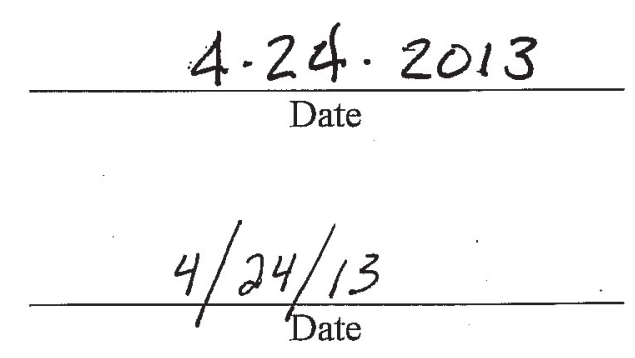




\begin{abstract}
Alloy 617 is the leading candidate material for an Intermediate Heat Exchanger (IHX) of the Very High Temperature Reactor (VHTR). To evaluate the behavior of this material in the expected service conditions, strain-controlled cyclic tests that include hold times up to $9000 \mathrm{~s}$ at maximum tensile strain were conducted at 850 and $950^{\circ} \mathrm{C}$. In terms of the total number of cycles to failure, the fatigue resistance at both temperatures decreased when a hold time was added at peak tensile strain. The magnitude of this effect depended upon the specific degradation mechanisms and whether they resulted in a change in fracture mode from transgranular in pure fatigue to intergranular in creep-fatigue for a particular temperature and strain range combination. Increases in the tensile hold duration beyond an initial value were not detrimental to the creep-fatigue resistance at $950^{\circ} \mathrm{C}$, but continued to degrade the lifetimes at $850^{\circ} \mathrm{C}$.
\end{abstract}




\section{ACKNOWLEDGEMENTS}

The authors would like to thank Richard Wright, Jill Wright, and Celine Cabet for thoughtful guidance and discussions regarding this subject matter. The authors would also like to acknowledge Joel Simpson and Randy Lloyd for conducting the extensive creep-fatigue testing, Tammy Trowbridge and Todd Morris for the considerable metallurgical work required for this study, and Jill Wright for data analysis of the fatigue and creep-fatigue cyclic testing. Transmission electron microscopy work carried out at the Boise State Center for Materials Characterization has been supported by NSF MRI Grant DMR0521315. This work was supported through the U.S. Department of EnergyNuclear Energy. 


\section{CONTENTS}

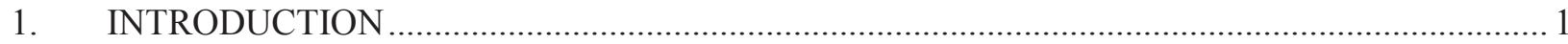

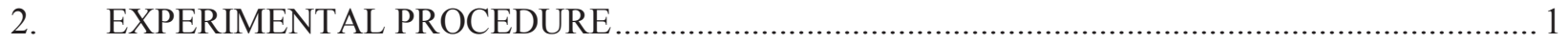

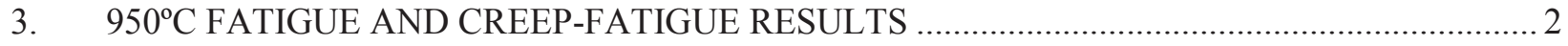

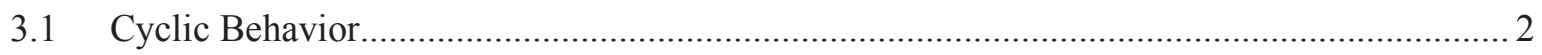

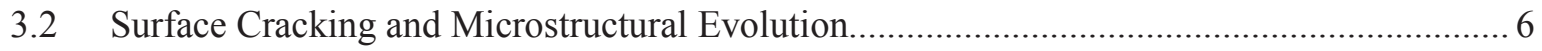

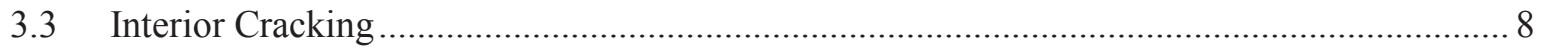

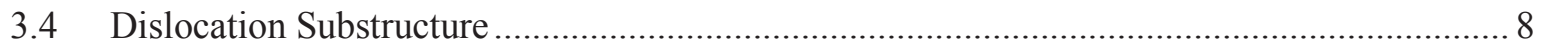

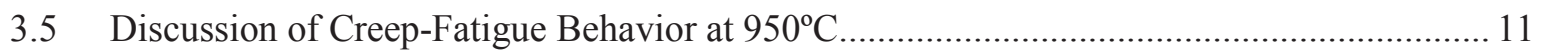

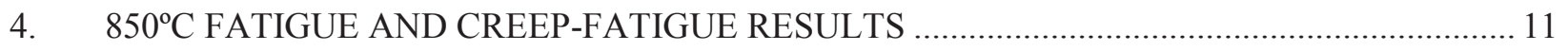

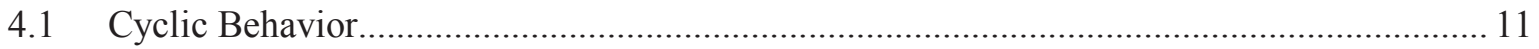

4.2 Microstructural Evolution During Cyclic Deformation ..................................................... 16

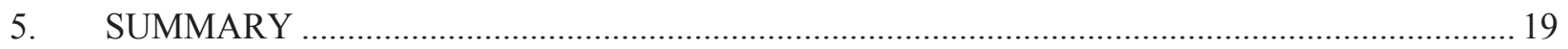

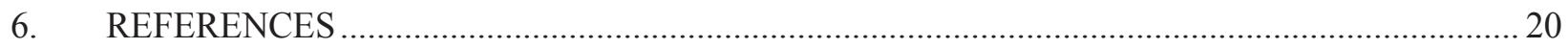

\section{FIGURES}

Figure 1. Plot of the total strain range (a) and inelastic strain range (b) as a function of cycles to failure for Alloy 617 in fatigue and creep-fatigue at $950^{\circ} \mathrm{C}$ at three strain ranges, $0.3 \%$, $0.6 \%$, and $1.0 \%$, for hold times of up to $9000 \mathrm{~s}$ (150 minutes). The appropriate CoffinManson relationship for the fatigue data is plotted as the dashed line in (b)..............................

Figure 2. Peak stress versus cycle curves for selected specimens at the $0.3 \%$ (a) and $1.0 \%$ (b) total strain range for fatigue and $600 \mathrm{~s}$ hold time creep-fatigue at $950^{\circ} \mathrm{C}$. 5

Figure 3. Hysteresis loops for specimens tested at $0.6 \%$ total strain and no hold and an $1800 \mathrm{~s}$ hold (a) and $0.3 \%$ total strain and no hold and a $600 \mathrm{~s}$ hold (b).

Figure 4. Plot of the rapid stress relaxation occurring during the tensile hold during creep-fatigue at $0.3 \%$ total strain (a). Plot of the peak tensile stresses and the relaxed stresses (open circles) versus cycle at $1.0 \%$ total strain (b).

Figure 5. Surface cracking in creep-fatigue of Alloy 617 cyclically deformed at $950^{\circ} \mathrm{C}$ and $0.3 \%$ total strain with a $600 \mathrm{~s}$ hold (a). Interior grain boundary cracking $(\mathrm{b}, \mathrm{c})$ and cavitation (d) in Alloy 617 cyclically deformed at $950^{\circ} \mathrm{C}$ and $0.3 \%$ total strain with a 180 s hold (b, c) and $0.6 \%$ total strain with a $1800 \mathrm{~s}$ hold test interrupted at $20 \%$ of life (d). The stress axis is horizontal in the plane of the page.

Figure 6. TEM images of specimens cycled at 1.0\% total strain (a) and $0.3 \%$ total strain (b) in fatigue at $950^{\circ} \mathrm{C}$ showing a cellular structure and planar deformation bands and annealing twins. A creep-fatigue specimen cycled at $950^{\circ} \mathrm{C}$ with a $600 \mathrm{sec}$ hold at a $1.0 \%$ total strain (c) and a $0.3 \%$ total strain (d) showing a subgrain structure with boundaries comprised of ordered dislocation networks and a lower dislocation density in the cell interiors. 
Figure 7. Low-energy hexagonal dislocation network in a tensile-hold creep-fatigue specimen tested at $950^{\circ} \mathrm{C}, 0.3 \%$ total strain, and a 600 s hold time. Two of the 2-beam conditions that render one dislocation segment type invisible are shown in (a) and (b) along with a multi-beam imaging condition (c) to provide contrast for the entire network. A schematic (d) illustrates the individual sense vectors comprising the imaged hexagonal network.

Figure 8. Plot of the total strain range (a) and inelastic strain range (b) as a function of cycles to failure for Alloy 617 in fatigue and creep-fatigue at $850^{\circ} \mathrm{C}$ at three strain ranges, $0.3 \%$ and $1.0 \%$, for hold times of up to 30 minutes. The plot in (b) also includes the $950^{\circ} \mathrm{C}$ fatigue and creep-fatigue data for comparison and the dashed line represents the CoffinManson relationship for the $950^{\circ} \mathrm{C}$ fatigue data.

Figure 9. Peak stresses as a function of cycle for a typical fatigue and creep-fatigue tests at $850^{\circ} \mathrm{C}$ and $0.3 \%$ total strain (a) and a $1.0 \%$ total strain (b).

Figure 10. Tenth cycle (a) and a midlife cycle (b) hysteresis loops from a typical fatigue and creep-fatigue tests at $850^{\circ} \mathrm{C}$ and $0.3 \%$ total strain.

Figure 11. Plot of the peak and valley strain values from a 3 minute hold creep-fatigue test at the $0.3 \%$ total strain range and $850^{\circ} \mathrm{C}$.

Figure 12. Tenth cycle (a) and a midlife cycle (b) hysteresis loops from a typical fatigue and creep-fatigue tests at $850^{\circ} \mathrm{C}$ and $1.0 \%$ total strain.

Figure 13. Typical stress relaxation curves from a midlife cycle of creep-fatigue tests at $850^{\circ} \mathrm{C}$ and $0.3 \%$ total strain (a) and $1.0 \%$ total strain (b).

Figure 14 . Transgranular surface cracking in a $0.3 \%$ total strain fatigue specimen cycled at $850^{\circ} \mathrm{C}$ (a). Intergranular surface cracking in a $0.3 \%$ total strain creep-fatigue specimen with a 30 minute tensile hold also cycled at $850^{\circ} \mathrm{C}$ (b). The stress axis is vertical and in the plane of the page.

Figure 15. Internal grain boundary cracking (separation) in a specimen tested in creep-fatigue at $0.3 \%$ total strain and a 10 minute hold time at $850^{\circ} \mathrm{C}$. The stress axis is vertical and in the plane of the page.

Figure 16. Length of individual internal grain boundary cracks in the gage section of specimens tested in creep-fatigue at $0.3 \%$ total strain (a) and $1.0 \%$ total strain (b) at $850^{\circ} \mathrm{C}$ for various hold times.

\section{TABLES}

Table 1. Alloy 617 plate composition in $\mathrm{wt} \%$.

Table 2. Summary of the fatigue and creep-fatigue data at $950^{\circ} \mathrm{C}$.................................................... 4

Table 3. Summary of the fatigue and creep-fatigue data at $850^{\circ} \mathrm{C}$.

Table 4. Cracking modes in fatigue and creep-fatigue specimens tested at $850^{\circ} \mathrm{C}$. It was not possible to determine the primary surface cracking mode from the sectioned specimen cycled at $0.3 \%$ total strain with a 3 minute hold. 


\section{ACRONYMS}

VHTR Very High Temperature Reactor

IHX Intermediate Heat Exchanger

SEM scanning electron microscope

TEM transmission electron microscope

DSA dynamic strain aging 


\section{Creep-Fatigue Behavior of Alloy 617 at 850 and $950^{\circ} \mathrm{C}$}

\section{INTRODUCTION}

The Very High Temperature Reactor (VHTR) is being developed as a nuclear system with helium as the primary coolant to transport thermal energy for the cogeneration of hydrogen and electricity. Conceptual design requires an outlet temperature of greater than $850^{\circ} \mathrm{C}$ to provide for the efficient generation of hydrogen, with a maximum expected outlet temperature of $950^{\circ} \mathrm{C}$ [1]. A critical component in the VHTR system for extracting thermal energy at these temperatures is the Intermediate Heat Exchanger (IHX), which will be required to operate at reactor outlet temperatures of up to $950^{\circ} \mathrm{C}$. The combination of very high temperature operation and long duration of service dictates the need for structural materials with good thermal stability as well as high temperature creep and oxidation resistance. Based on these material requirements, the nickel base alloy UNS N06617, Alloy 617, is the leading IHX candidate alloy [1].

Creep-fatigue deformation is expected to be a significant contributor to the factors that limit the useful life of the IHX in the VHTR nuclear system [1]. This deformation mode occurs as a result of power transients during operation and startup/shutdown cycles, each of which produces cyclic loading, while extended times at high-stress during steady power operation induce creep deformation. To approximate the expected deformation mode in a laboratory setting, creep-fatigue testing introduces a hold time in a strain-controlled fatigue cycle. Previous work on Alloy 617 has suggested that it is a tensile dwell sensitive alloy [2], and therefore this type of loading was the focus of this work.

Creep-fatigue interactions are often depicted microstructurally as the combined effects of fatigue damage and creep damage. The fatigue component is considered to be the initiation and propagation of surface cracks, while the creep component is manifested as creep voids on interior grain boundaries (or wedge cracking at triple junctions), each of which develop independently [3-5]. The linking of these two deformation modes results in an accelerated failure [3-5].

The continuous-cycle fatigue and creep-fatigue (with dwell times in tension of up to $9000 \mathrm{~s}$ ) behavior of Alloy 617 at $850^{\circ} \mathrm{C}$ and $950^{\circ} \mathrm{C}$ with $0.3 \%, 0.6 \%\left(950^{\circ} \mathrm{C}\right.$ only), and $1.0 \%$ total strain ranges in air has been investigated. Detailed evaluations of the specific failure mechanisms have also been addressed to support analysis of the aforementioned data. Microstructural evidence is provided to compliment the reduced failure lives with the addition of a constant strain hold time observed at both temperatures and the significant cyclic softening present at $950^{\circ} \mathrm{C}$.

\section{EXPERIMENTAL PROCEDURE}

Cylindrical creep-fatigue specimens, 7.5-mm-diameter in the reduced section with a gage length of $12 \mathrm{~mm}$, were machined from an Alloy 617 solution annealed plate with the long axis of the specimens aligned along the rolling direction. The composition of the Alloy 617 plate is given in Table 1. Although the average grain size of the plate is quantified as approximately $150 \mu \mathrm{m}$, significant grain size inhomogeniety is present in the microstructure [6].

Table 1. Alloy 617 plate composition in $\mathrm{wt} \%$.

\begin{tabular}{|l|c|c|c|c|c|c|c|c|c|c|c|}
\hline Alloy & $\mathrm{Ni}$ & $\mathrm{C}$ & $\mathrm{Cr}$ & $\mathrm{Co}$ & $\mathrm{Mo}$ & $\mathrm{Fe}$ & $\mathrm{Al}$ & $\mathrm{Ti}$ & $\mathrm{Si}$ & $\mathrm{Cu}$ & $\mathrm{Mn}$ \\
\hline 617 & Bal. & 0.05 & 22.2 & 11.6 & 8.6 & 1.6 & 1.1 & 0.4 & 0.1 & 0.04 & 0.1 \\
\hline
\end{tabular}

Fully-reversed strain-controlled continuous-cycle fatigue and tensile-hold creep-fatigue testing was conducted on Alloy 617 at $850^{\circ} \mathrm{C}$ and $950^{\circ} \mathrm{C}$ in air at three strain ranges, $0.3 \%, 0.6 \%\left(950^{\circ} \mathrm{C}\right.$ only), and $1.0 \%$. Cyclic testing was conducted on servo-hydraulic test machines in axial strain-control mode utilizing either radio-frequency induction heating or a three-zone radiant furnace to heat the specimens. Continuous-cycle fatigue testing followed a triangular waveform, while creep-fatigue testing followed a trapezoidal waveform with hold times of $180 \mathrm{~s}$ up to $9000 \mathrm{~s}$ imposed at the maximum tensile strain. In all cases, a strain-controlled ramp rate of $10^{-3} / \mathrm{s}$ was employed. Several intermediate strain cycles were applied during a limited number of initial cycles prior to reaching the target strain level on most of the tests being evaluated, a procedure that was employed to prevent overshooting the 
target strain on the first cycle - a common occurrence for Alloy 617 at these high temperatures even at the low strain values being imparted, as the material is deforming in a fully plastic regime at $950^{\circ} \mathrm{C}$.

For the continuous-cycle fatigue and tensile-hold creep-fatigue, the number of cycles to failure, $\mathrm{N}_{\mathrm{f}}$, was defined as a $20 \%$ decrease in the ratio of the peak tensile stress to the peak compressive stress from the point, $\mathrm{N}_{\mathrm{o}}$, at which this ratio initially deviates from a constant trend. Actual test completion was based upon a predetermined drop in load and prior to actual specimen separation; when the set load drop was detected, the test automatically switched to zero load and power to the heat source was shut off. A fatigue or creep-fatigue test result is considered trend (T) data if an anomaly occurred during testing, such as a concern with temperature control of the specimen. The letter "Y" is used to denote a valid test in the summary data tables in a column with the header "valid".

The gage sections of the deformed specimens were cut into two halves along the stress axis to expose a plane containing the largest observed surface crack. Half of the gage section was mounted, polished, and etched with a $2 \%$ bromine and $98 \%$ methanol solution. Metallurgical evaluation was conducted using optical microscopy and a Quanta 650 Field Emission Gun Scanning Electron Microscope (SEM). The remaining half of the gage section was mechanically thinned for the extraction of transmission electron microscopy (TEM) foils. The longitudinal portion of the gage section was first reduced to approximately $125 \mu \mathrm{m}$ and then punched into $3 \mathrm{~mm}$ discs. The discs were electropolished using a twin jet TenuPol-5 polisher with a solution of $10 \%$ perchloric acid in ethanol at approximately $-15{ }^{\circ} \mathrm{C}$. Microstructural characterization on the polished foils was conducted using a JOEL JEM-2010 HR Analytical TEM operating at $200 \mathrm{kV}$.

\section{3. $950^{\circ} \mathrm{C}$ FATIGUE AND CREEP-FATIGUE RESULTS}

\subsection{Cyclic Behavior}

For the fatigue and tensile-hold creep-fatigue testing of Alloy 617 conducted at $950^{\circ} \mathrm{C}$ at the three defined strain ranges, Figure 1(a) and Table 2 show the cycles to failure as a function of hold time. As previously observed for Alloy 617 [2, 3, 7], the addition of a tensile hold time in creep-fatigue decreased the total cycle life. For the specific conditions studied here, the cycle lifetimes for creep-fatigue versus continuous-cycle fatigue are reduced by roughly a factor of 2 for all strain ranges. Increasing the duration of the hold time beyond the $180 \mathrm{~s}$ minimum value tested had no further influence on the number of cycles to failure. Also noted was that more scatter is present in the fatigue lifetimes at the $0.3 \%$ strain range than at the higher strain ranges. A further characteristic unique to the $0.3 \%$ strain range is that the detriment in creep-fatigue cycle life is directly related to the increase in inelastic strain range with the addition of a tensile hold, as illustrated in Figure 1(b). In other words, the creep-fatigue behavior at $0.3 \%$ total strain follows the Coffin-Manson relationship, $\mathrm{N}_{\mathrm{f}}^{\beta} \times \varepsilon_{i n}=\mathrm{C}$, typically only observed for the continuous-cycle fatigue behavior. In the equation shown, $\mathrm{N}_{\mathrm{f}}$ is the number of cycles to failure, $\varepsilon_{i n}$ is the inelastic strain range (defined here as width of the hysteresis loop at zero stress), and $\beta$

and $\mathrm{C}$ are constants. An important distinction, however, is that the $0.6 \%$ and $1.0 \%$ total strain range tensile-hold creep-fatigue data do not follow Coffin-Manson fatigue behavior. 


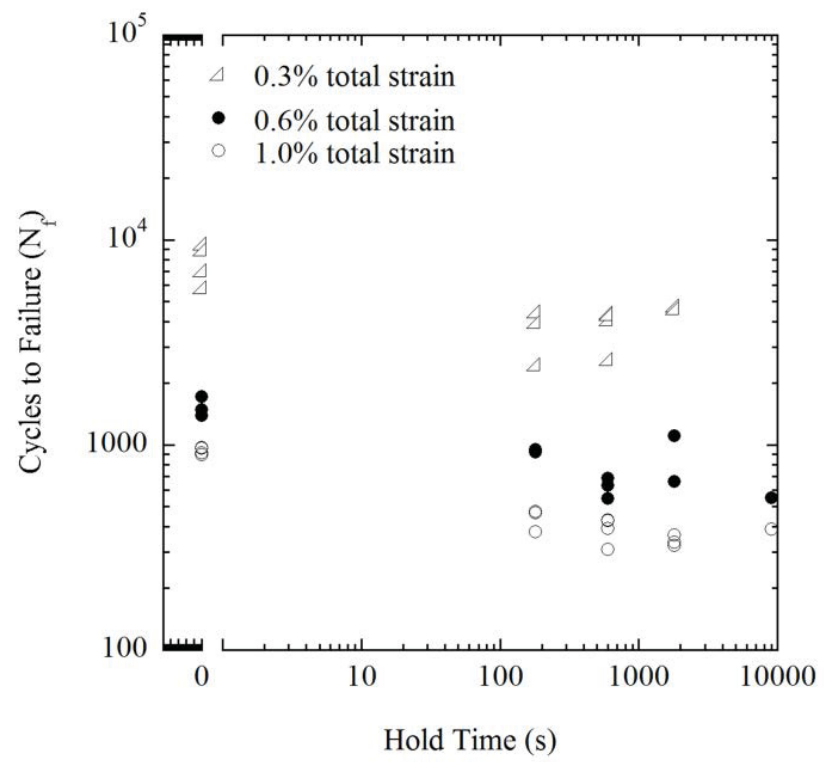

(a)

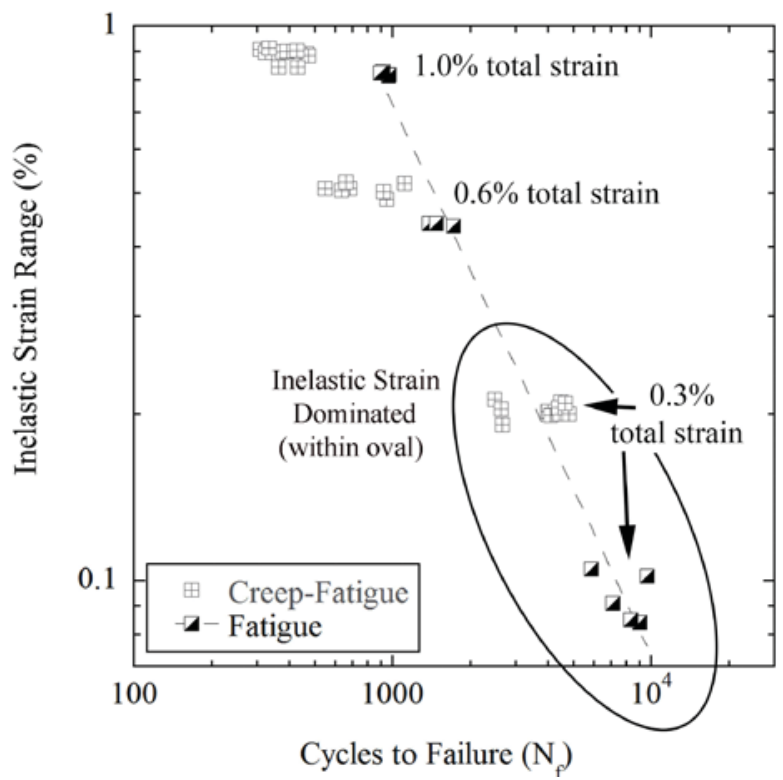

(b)

Figure 1. Plot of the total strain range (a) and inelastic strain range (b) as a function of cycles to failure for Alloy 617 in fatigue and creep-fatigue at $950^{\circ} \mathrm{C}$ at three strain ranges, $0.3 \%, 0.6 \%$, and $1.0 \%$, for hold times of up to $9000 \mathrm{~s}$ (150 minutes). The appropriate Coffin-Manson relationship for the fatigue data is plotted as the dashed line in (b). 
Table 2. Summary of the fatigue and creep-fatigue data at $950^{\circ} \mathrm{C}$.

\begin{tabular}{|c|c|c|c|c|c|c|c|c|c|c|c|c|c|c|c|}
\hline \multirow[t]{3}{*}{ Specimen } & $t_{\mathrm{h}}$ & $\Delta \varepsilon_{\mathrm{t}}$ & \multicolumn{5}{|c|}{ At Cycle 10} & \multicolumn{5}{|c|}{ Midlife } & \multirow[b]{2}{*}{$\begin{array}{l}\text { Cycles } \\
\text { to } \\
\text { Initiation }\end{array}$} & \multirow[b]{2}{*}{$\begin{array}{c}\text { Cycles } \\
\text { to Failure }\end{array}$} & \multirow[b]{2}{*}{ Valid } \\
\hline & & & $\sigma_{\max }$ & $\sigma_{\min }$ & $\sigma_{\mathrm{h} \text {-start }}$ & $\sigma_{\text {h-end }}$ & $\Delta \varepsilon_{\text {in }}$ & $\sigma_{\max }$ & $\sigma_{\min }$ & $\sigma_{\text {h-start }}$ & $\sigma_{\text {h-end }}$ & $\Delta \varepsilon_{\text {in }}$ & & & \\
\hline & (min) & $(\%)$ & (MPa) & (MPa) & (MPa) & (MPa) & $(\%)$ & (MPa) & (MPa) & (MPa) & (MPa) & $(\%)$ & $\left(\mathrm{N}_{0}\right)$ & $\left(\mathrm{N}_{20}\right)$ & \\
\hline A-20 & 0 & 0.3 & 161.2 & -168.4 & & & 0.0344 & 163.1 & -164.9 & & & 0.0955 & 8639 & 9641 & $\mathrm{~T}$ \\
\hline B-1 & 0 & 0.3 & 169.3 & -163.5 & & & 0.1035 & 168.6 & -167.3 & & & 0.1051 & 5033 & 5867 & $\mathrm{Y}$ \\
\hline B-3 & 0 & 0.3 & 172.6 & -166.5 & & & 0.0436 & 179.4 & -166.5 & & & 0.0791 & 8139 & 9054 & $\mathrm{~T}$ \\
\hline F-12 & 0 & 0.3 & 163.5 & -167.9 & & & 0.0927 & 161.2 & -164.4 & & & 0.0864 & 6377 & 7133 & $\mathrm{Y}$ \\
\hline $315-16$ & 0 & 0.3 & 169.1 & -168.4 & & & 0.0720 & 165.4 & -166.0 & & & 0.0748 & 7863 & 8333 & $\mathrm{~T}$ \\
\hline F-14 & 3 & 0.3 & 117.3 & -142.1 & 113.5 & 16.4 & 0.2068 & 88.6 & -110.9 & 87.37 & 11.2 & 0.1971 & 3889 & 4486 & $\mathrm{Y}$ \\
\hline B-5 & 3 & 0.3 & 137.8 & -170.9 & 130.6 & 19.3 & 0.1925 & 111.3 & -140.4 & 109.0 & 12.8 & 0.1920 & 2600 & 3984 & $\mathrm{Y}$ \\
\hline B-6 & 3 & 0.3 & 132.5 & -157.9 & 131.5 & 16.4 & 0.2044 & 113.5 & -125.2 & 108.8 & 16.6 & 0.2015 & 1944 & 2485 & $\mathrm{Y}$ \\
\hline B-7 & 10 & 0.3 & 147.9 & -167.4 & 141.9 & 15.7 & 0.1979 & 108.5 & -130.6 & 104.2 & 13.5 & 0.1886 & 3583 & 4096 & $\mathrm{Y}$ \\
\hline A-22 & 10 & 0.3 & 132.7 & -166.0 & 131.9 & 15.9 & 0.1969 & 93.8 & -123.5 & 91.01 & 11.1 & 0.1870 & 3569 & 4430 & $\mathrm{~T}$ \\
\hline B-9 & 10 & 0.3 & 142.9 & -163.7 & 138.8 & 13.4 & 0.1973 & 111.1 & -130.3 & 110.3 & 19.5 & 0.1915 & 2183 & 2623 & $\mathrm{Y}$ \\
\hline F-15 & 10 & 0.3 & 121.2 & -152.1 & 116.8 & 11.0 & 0.2071 & 81.9 & -104.2 & 81.4 & 8.2 & 0.1972 & 3736 & 4361 & $\mathrm{Y}$ \\
\hline B-11 & 30 & 0.3 & 137.4 & -170.7 & 135.4 & 14.5 & 0.1970 & 92.4 & -132.5 & 90.5 & 10.7 & 0.1854 & 4194 & 4832 & $\mathrm{~T}$ \\
\hline B-8 & 30 & 0.3 & 126.4 & -154.8 & 124.0 & 8.7 & 0.2150 & 92.6 & -111.6 & 90.8 & 13.4 & 0.2015 & 4375 & 4650 & $\mathrm{~T}$ \\
\hline $43-14$ & 30 & 0.3 & 155.2 & -176.1 & 155.1 & 12.8 & 0.2059 & 105.3 & -145.5 & 107.5 & 4.8 & 0.1954 & 2508 & 2653 & $\mathrm{Y}$ \\
\hline B-13 & 0 & 0.6 & 148.3 & -147.4 & & & 0.4264 & 144.3 & -144.8 & & & 0.4235 & 783 & 1722 & $\mathrm{Y}$ \\
\hline B-14 & 0 & 0.6 & 133.5 & -131.7 & & & 0.4382 & 130.5 & -127.4 & & & 0.4323 & 762 & 1390 & $\mathrm{Y}$ \\
\hline B-15 & 0 & 0.6 & 144.1 & -142.1 & & & 0.4321 & 141.0 & -139.8 & & & 0.4319 & 826 & 1480 & $\mathrm{Y}$ \\
\hline A-23 & 3 & 0.6 & 155.6 & -172.3 & 149.9 & 29.7 & 0.4756 & 136.3 & -145.1 & 128.7 & 26.4 & 0.4950 & 450 & 950 & $T$ \\
\hline B-16 & 3 & 0.6 & 139.1 & -149.1 & 132.9 & 30.5 & 0.4925 & 120.8 & -121.7 & 119.9 & 23.5 & 0.4961 & 297 & 922 & $\mathrm{Y}$ \\
\hline B-18 & 10 & 0.6 & 139.7 & -151.7 & 136.7 & 19.4 & 0.4945 & 121.9 & -121.6 & 119.4 & 17.3 & 0.4971 & 402 & 686 & $\mathrm{Y}$ \\
\hline B-19 & 10 & 0.6 & 151.5 & -166.6 & 148.2 & 21.5 & 0.4866 & 136.5 & -136.9 & 134.4 & 21.6 & 0.4936 & 416 & 634 & $\mathrm{Y}$ \\
\hline A-14 & 10 & 0.6 & 142.8 & -156.9 & 139.4 & 21.6 & 0.4948 & 127.9 & -125.9 & 125.5 & 21.7 & 0.4974 & 312 & 547 & $\mathrm{Y}$ \\
\hline B-21 & 30 & 0.6 & 125.0 & -139.7 & 122.3 & 12.8 & 0.5111 & 102.8 & -103.5 & 100.2 & 9.9 & 0.5165 & 367 & 661 & $\mathrm{~T}$ \\
\hline F-13 & 30 & 0.6 & 130.5 & -155.0 & 127.7 & 14.1 & 0.5001 & 86.7 & -95.3 & 83.9 & 7.8 & 0.5003 & 860 & 1110 & $\mathrm{~T}$ \\
\hline 416-18 & 30 & 0.6 & 149.3 & -173.3 & 148.6 & 29.9 & 0.4908 & 145.2 & -158.0 & 143.0 & 18.6 & 0.4904 & 410 & 525 & $\mathrm{Y}$ \\
\hline $315-1$ & 0 & 1.0 & 158.2 & -164.6 & & & 0.7980 & 150.2 & -155.8 & & & 0.7910 & 593 & 963 & $\overline{\mathrm{Y}}$ \\
\hline E-11 & 0 & 1.0 & 137.2 & -143.6 & & & 0.8238 & 127.7 & -124.0 & & & 0.8119 & 666 & 972 & $\mathrm{Y}$ \\
\hline E-12 & 0 & 1.0 & 139.4 & -137.3 & & & 0.8214 & 123.8 & -119.6 & & & 0.8161 & 447 & 916 & $\mathrm{Y}$ \\
\hline E-13 & 0 & 1.0 & 140.6 & -136.6 & & & 0.8221 & 128.1 & -123.3 & & & 0.8161 & 561 & 897 & Y \\
\hline A-6 & 3 & 1.0 & 142.5 & -140.6 & 131.1 & 23.1 & 0.8887 & 121.5 & -121.6 & 117.7 & 28.9 & 0.8890 & 165 & 376 & $\mathrm{~T}$ \\
\hline F-5 & 3 & 1.0 & 140.6 & -149.1 & 137 & 27.1 & 0.8819 & 116.1 & -122.8 & 112.7 & 23.0 & 0.8810 & 172 & 465 & $\mathrm{Y}$ \\
\hline B-12 & 3 & 1.0 & 158.7 & -170.3 & 154.7 & 26.7 & 0.8739 & 134.8 & -147.2 & 132.4 & 27.3 & 0.8737 & 330 & 472 & $\mathrm{Y}$ \\
\hline A-13 & 10 & 1.0 & 135.0 & -136.1 & 124.7 & 22.4 & 0.8993 & 117.4 & -113.3 & 115.1 & 22.1 & 0.8971 & 148 & 308 & $\mathrm{Y}$ \\
\hline F-4 & 10 & 1.0 & 144.1 & -155.6 & 141.4 & 21.8 & 0.8848 & 120.0 & -128.1 & 119.7 & 19.5 & 0.8791 & 145 & 391 & $\mathrm{Y}$ \\
\hline E-1 & 10 & 1.0 & 131.5 & -147.4 & 119.6 & 14.3 & 0.8930 & 105.6 & -116.8 & 104.3 & 16.5 & 0.8890 & 308 & 427 & $T$ \\
\hline E-8 & 10 & 1.0 & 119.3 & -134.0 & 114.4 & 15.7 & 0.9047 & 108.3 & -115.8 & 106.5 & 21.8 & 0.8234 & 311 & 430 & $\mathrm{Y}$ \\
\hline E-6 & 30 & 1.0 & 145.5 & -147.3 & 135.2 & 24.5 & 0.8972 & 136.0 & -128.1 & 129 & 25.2 & 0.8907 & 217 & 322 & $\mathrm{Y}$ \\
\hline E-7 & 30 & 1.0 & 124.0 & -139.7 & 120.1 & 12.0 & 0.9111 & 105.9 & -116.7 & 104.6 & 11.5 & 0.8280 & 271 & 364 & $\mathrm{~T}$ \\
\hline E-9 & 30 & 1.0 & 140.2 & -157.6 & 131.8 & 16.8 & 0.9047 & 125.7 & -125.8 & 123.6 & 18.2 & 0.9080 & 226 & 334 & $\mathrm{Y}$ \\
\hline E-10 & 150 & 1.0 & 131.8 & -152.0 & 127.4 & 5.8 & 0.9106 & 105.1 & -115.4 & 101.1 & 5.8 & 0.8631 & 268 & 386 & $\mathrm{Y}$ \\
\hline
\end{tabular}

Figure 2 shows the individual peak stresses as a function of cycle for specimens tested at the $0.3 \%$ and $1.0 \%$ total strain range. In fatigue, the peak stress versus cycle trends at all three strain ranges exhibit a region in which there is a plateau in stress. This plateau is reached early in cycling and extends until the macrocrack initiation, designated as $\mathrm{N}_{\mathrm{i}}$. For creep-fatigue cycling, illustrated for the $600 \mathrm{~s}$ hold time condition at the lowest and highest strain range, cyclic softening is observed very early in cycling and persists until the rapid stress drop near failure. The duration of the hold time did not appear to substantially influence the peak stress versus cycle curve, specifically with regard to the amount of cyclic softening. At the $0.3 \%$ strain range shown in Figure 2(a), there is an initial rapid decrease in peak tensile and compressive stress that later steadies at a slower, more constant softening rate. At the higher $1.0 \%$ total strain range illustrated in Figure 2(b), a relatively constant rate of cyclic softening is maintained during creep-fatigue, and it is again observed that the softening is more severe than in the case of continuous-cycle fatigue deformation over the same strain range.

Fatigue and creep-fatigue midlife hysteresis loops are shown in Figure 3(a) for a test with $0.6 \%$ total strain and Figure $3(\mathrm{~b})$ for a test with $0.3 \%$ total strain, in each case illustrating that the addition of a hold period increased the amount of inelastic strain and resulted in a decay in the measured stress level to less than $20 \mathrm{MPa}$ over the strain-controlled hold. Stress relaxation during the hold is shown in more detail for the $0.3 \%$ strain range in Figure 4(a); the stresses relax rapidly, and although not shown in this figure, the stress relaxation occurs at the 
same rate regardless of the strain range. A constant low stress (less than $20 \mathrm{MPa}$ ) is achieved within about $600 \mathrm{~s}$ of the hold initiation. The approximate relaxed stress for selected cycles, along with the peak tensile and compressive stresses, is shown in Figure 4(b) for the 1.0\% total strain range at each hold time. The relaxed stresses are also similar for all three strain ranges regardless of hold time; the data are provided numerically in Table 2.

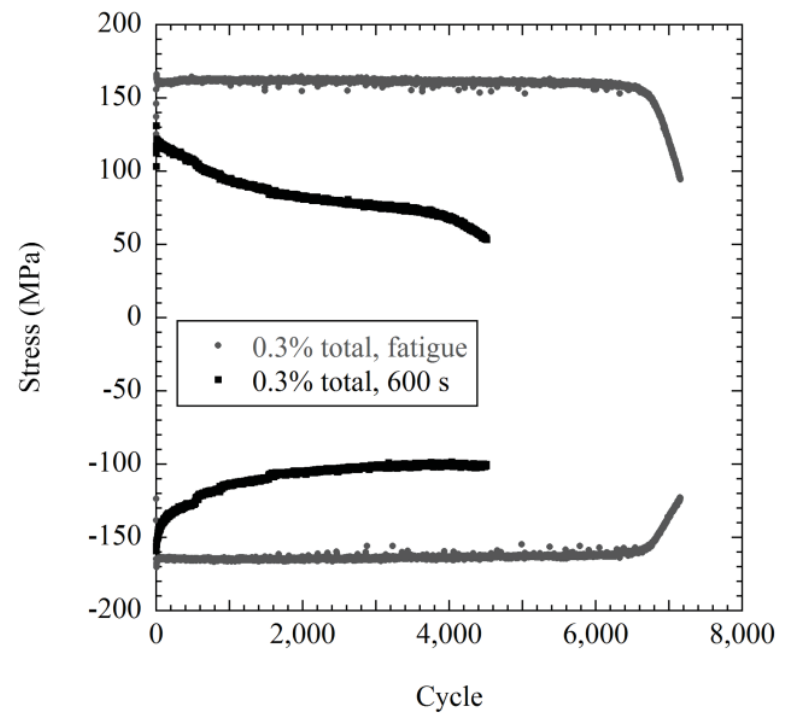

(a)

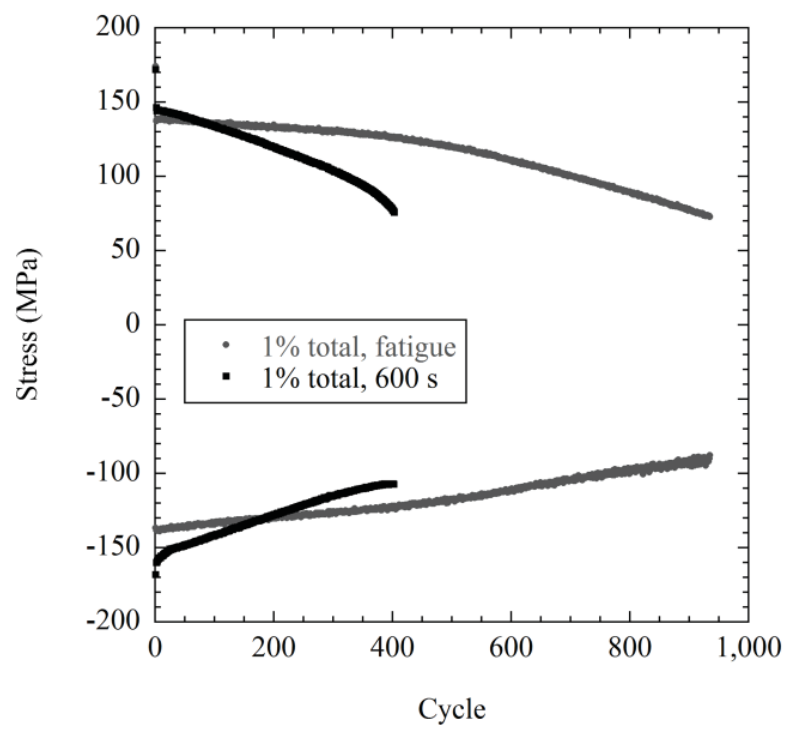

(b)

Figure 2. Peak stress versus cycle curves for selected specimens at the $0.3 \%$ (a) and $1.0 \%$ (b) total strain range for fatigue and $600 \mathrm{~s}$ hold time creep-fatigue at $950^{\circ} \mathrm{C}$.

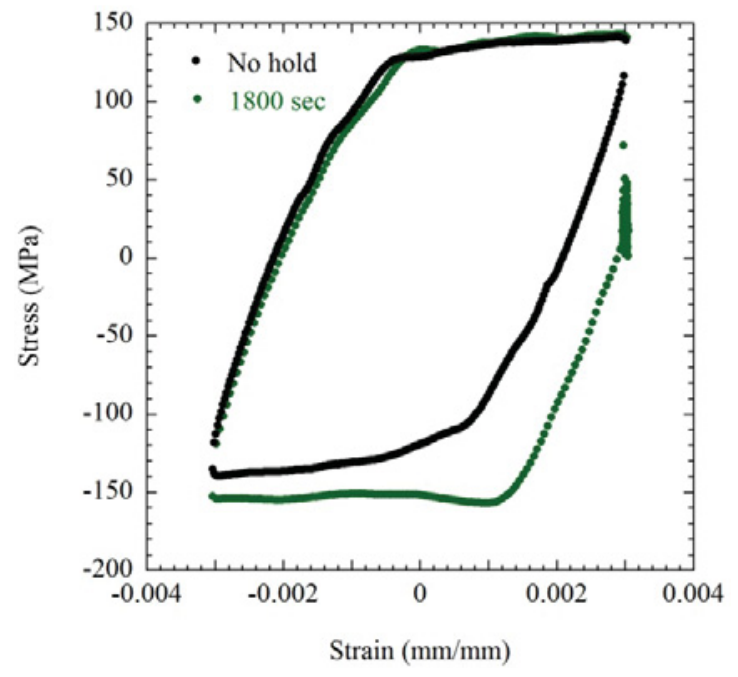

(a)

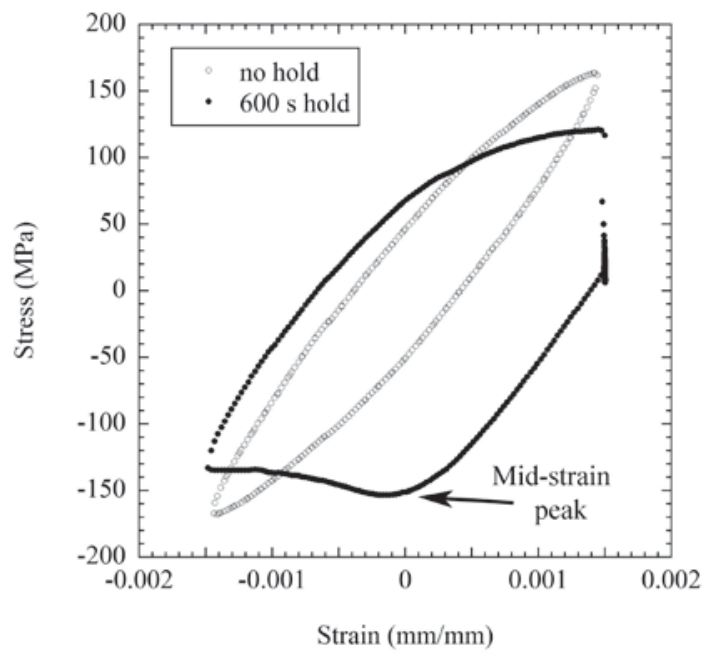

(b)

Figure 3. Hysteresis loops for specimens tested at $0.6 \%$ total strain and no hold and an $1800 \mathrm{~s}$ hold (a) and $0.3 \%$ total strain and no hold and a $600 \mathrm{~s}$ hold (b). 


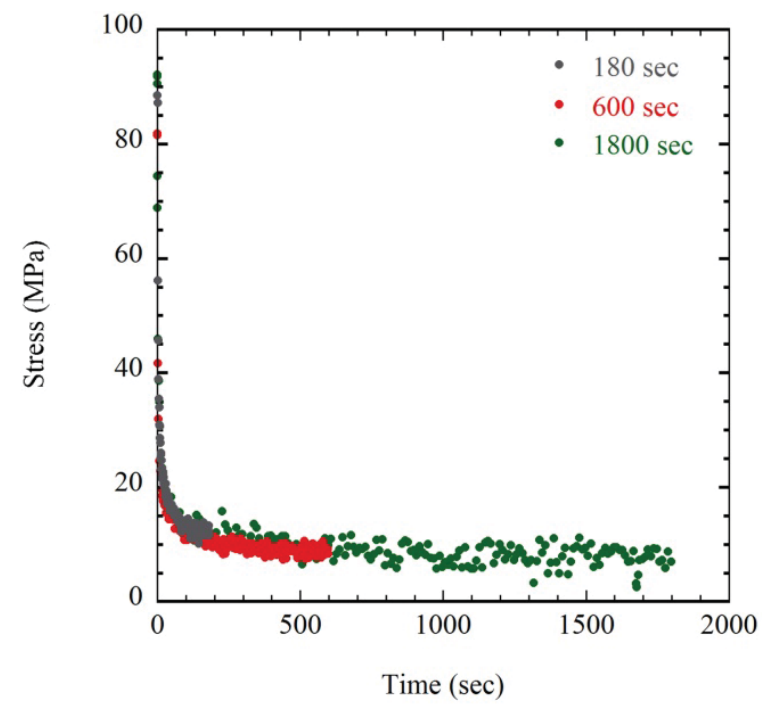

(a)

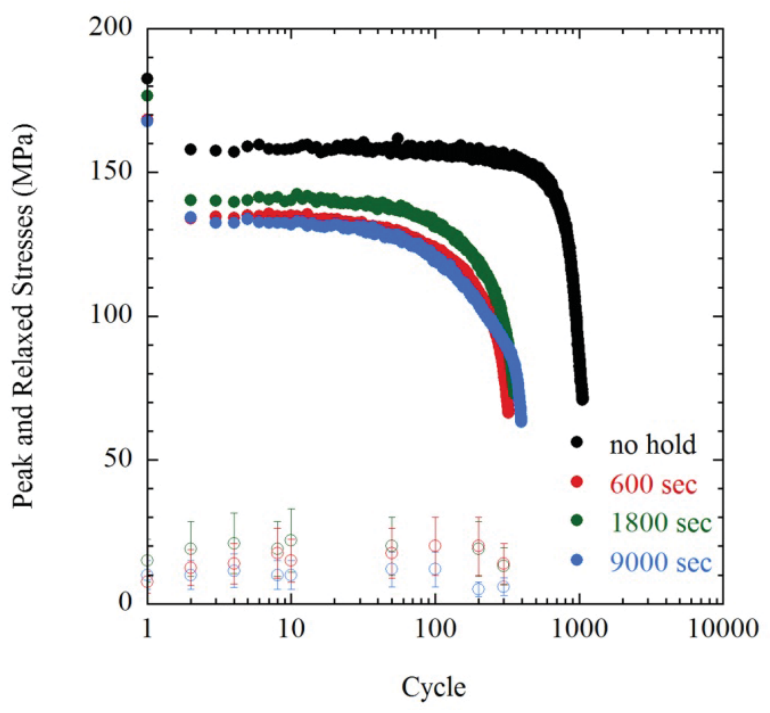

(b)

Figure 4. Plot of the rapid stress relaxation occurring during the tensile hold during creep-fatigue at $0.3 \%$ total strain (a). Plot of the peak tensile stresses and the relaxed stresses (open circles) versus cycle at $1.0 \%$ total strain (b).

\subsection{Surface Cracking and Microstructural Evolution}

The surfaces of fatigue specimens exhibited little change after deformation. Characterization reveals that a thin Cr-rich oxide can be detected on the surface coupled with a shallow zone depleted of grain boundary carbides. This lack of appreciable change is likely due to the short duration of the fatigue tests, which last from 820 hours at $950^{\circ} \mathrm{C}$. The increased test times during creep-fatigue result in a more dramatic evolution of the surface microstructure. Figure 5(a) is a cross-section through the surface of a failed creep-fatigue specimen at $0.3 \%$ strain (approximately $525 \mathrm{hrs}$ test time) showing a long primary crack and a secondary surface crack. A Cr-rich oxide scale has formed on the surface and in the near-surface region the internal aluminum has oxidized, forming a network of small precipitates. A region depleted of grain boundary carbides is also present beneath the exposed specimen surface. 


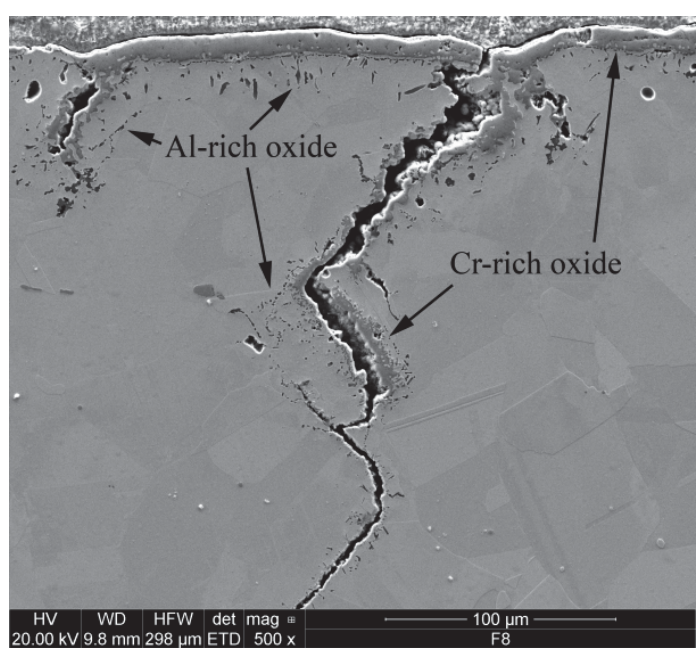

(a)

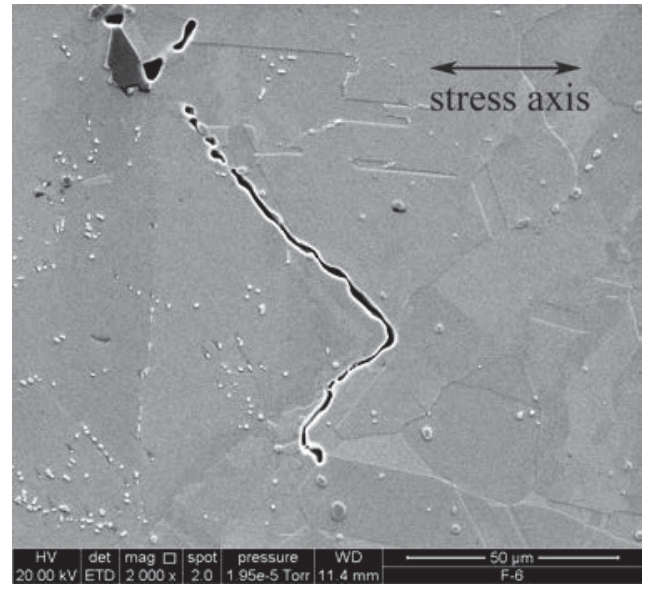

(c)

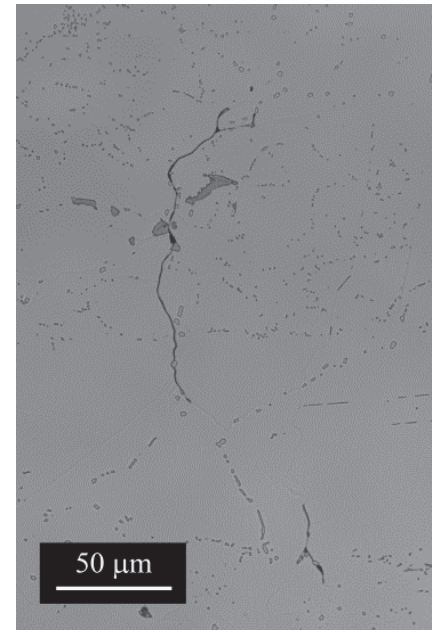

(b)

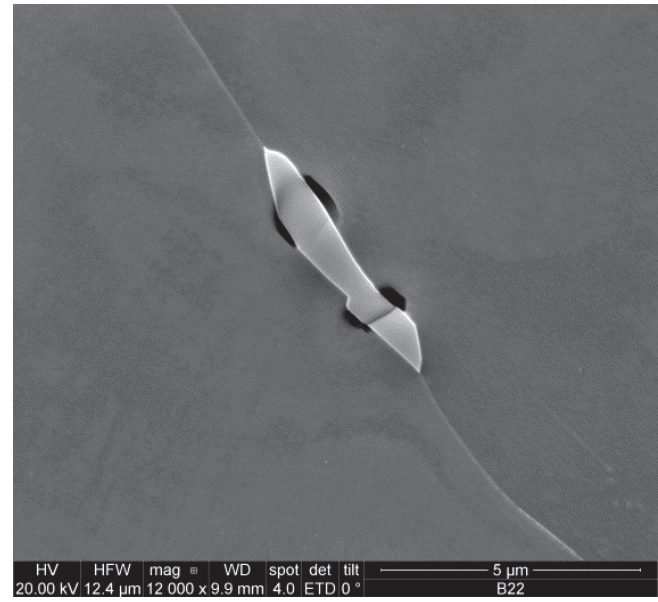

(d)

Figure 5. Surface cracking in creep-fatigue of Alloy 617 cyclically deformed at $950^{\circ} \mathrm{C}$ and $0.3 \%$ total strain with a $600 \mathrm{~s}$ hold (a). Interior grain boundary cracking (b, c) and cavitation (d) in Alloy 617 cyclically deformed at $950^{\circ} \mathrm{C}$ and $0.3 \%$ total strain with a $180 \mathrm{~s}$ hold $(\mathrm{b}, \mathrm{c})$ and $0.6 \%$ total strain with a $1800 \mathrm{~s}$ hold test interrupted at $20 \%$ of life (d). The stress axis is horizontal in the plane of the page.

The surface cracking morphology is similar in each of the three strain ranges evaluated at $950^{\circ} \mathrm{C}$. In continuous-cycle fatigue, the primary crack initiates and propagates in a transgranular manner and secondary intergranular cracks are not typically observed. In creep-fatigue, by contrast, the crack propagation mode is intergranular. As shown for the primary intergranular crack highlighted in Figure 5(a), a Cr-rich oxide forms along the adjacent flanks of the crack and the region surrounding the crack is depleted of grain boundary carbides. Fine Al-rich oxides also form at grain boundaries that intersect the exposed crack area. It is difficult to determine whether initiation of the primary crack occurs intergranularly or transgranularly in creep-fatigue, owing to the thick oxide layer that surrounds the cracks obscuring initiation features along with the depletion of grain boundary carbides that would otherwise delineate grain boundary locations. Based on the many shorter secondary cracks which start at oxidized grain boundaries, however, it is likely that the primary crack also initiated intergranularly. The addition of a hold time results in many of the grain boundaries that intersect the specimen surface evolving into secondary cracks. These secondary surface cracks extend deeper than the internal Al-rich oxides and are filled with a Cr-rich oxide. 


\subsection{Interior Cracking}

No large creep voids, typical of those observed during tertiary creep in nickel-base alloys [13] and commonly described as round micrometric cavities at bulk grain boundaries, were observed in any of the failed specimens. Instead, as is shown in Figures 5(b) and 5(c), numerous cracks and small cavities are observed in the interior of the deformed creep-fatigue specimens. These interior cracks, with measured lengths varying from $5 \mu \mathrm{m}$ up to several grain diameters, are not surface connected and do not contain any evidence of an oxide. These features are not observed in any of the fatigue specimens.

Analysis and quantification of the interior cracking in the creep-fatigue specimens within a rectangular area $6 \mathrm{~mm}$ in width (3 mm above and below the primary surface crack) across the entire gage section of a longitudinal slice revealed that interior cracking is not preferentially located near the primary crack, but instead is distributed at certain grain boundaries within the gage section. Following failure, the interior cracks are thin (having widths of a few hundreds of $\mathrm{nm}$ ) and generally follow grain boundaries either perpendicular to or at angles up to $45^{\circ}$ relative to the stress axis. In failed specimens, the majority of interior grain boundaries are absent of cracking or cavitation at magnifications of up to $100,000 \times$. The size distribution of the interior cracks is not significantly different for any of the hold times or strain ranges based on an analysis of variance (ANOVA) comparing each of the test populations. The summative length of cracked grain boundaries and the total number of cracked grain boundaries also do not vary systematically with strain range or hold time.

\subsection{Dislocation Substructure}

TEM imaging of fatigue and creep-fatigue specimens at failure for the 0.3 and $1 \%$ total strain range provides a general correlation between dislocation substructures and observed cyclic response based on test conditions. A significant amount of grain-to-grain variation is observed in the local dislocation substructure of the deformed material, and generalized descriptions regarding these substructures are made here with that understanding. As a result of grain sizes and shapes varying greatly throughout the bulk specimen along with the inherent irregularity of carbide distributions, numerous observations have been compiled in order to capture and classify the most representative microstructures at the length scales of single grains and cells. For the purpose of this work, cells are defined as three-dimensional structures comprised of walls of tangled dislocations. Subgrains are defined as similar structures, except that subgrain boundaries consist of distinctly ordered arrangements of dislocations.

At failure in continuous-cycle fatigue, there exist regions consisting of cellular structures, as shown for a representative area in Figure 6(a), and other regions that are absent of any sort of cell structure. Cell walls consist primarily of tangled dislocations, although select boundaries are present that exhibit advanced dislocation rearrangement into more ordered structures. Numerous planar deformation bands and annealing twins (Figure 6[b]) are also present throughout the microstructure and often serve as a boundary for an adjacent cell. These planar deformation bands frequently terminate at carbides, essentially connecting proximate intragranular carbide populations in a single cell structure. Ordered arrays of dislocation pile-ups at both grain boundaries and at large precipitates are present throughout. Of particular note is the overall lack of mobile dislocations throughout the matrix relative to the amount of dislocations in the cell walls, dislocation pile-ups, and planar deformation bands. 


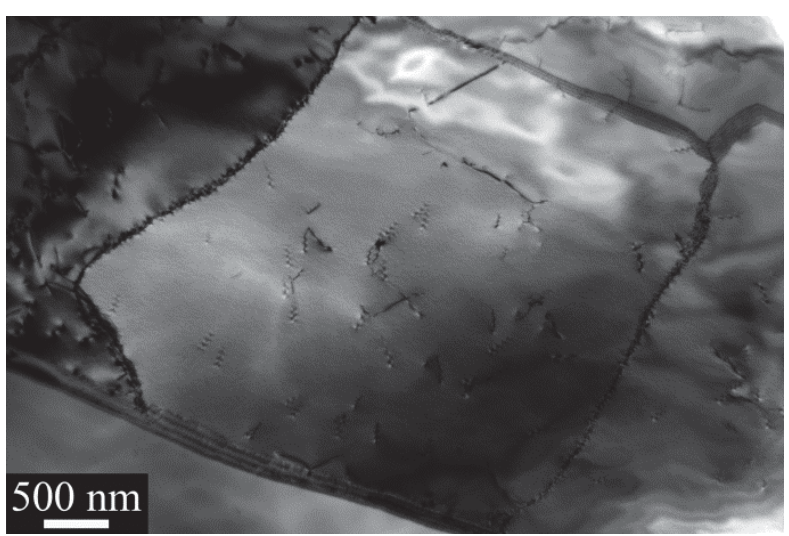

(a)

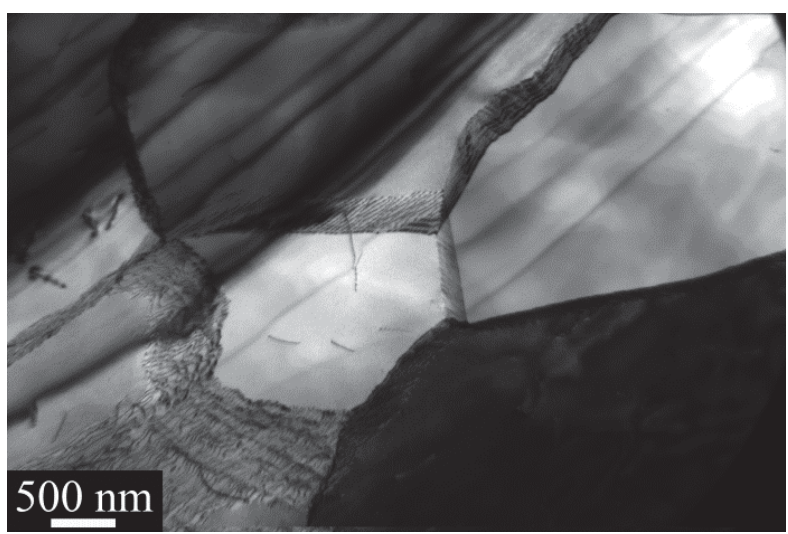

(c)

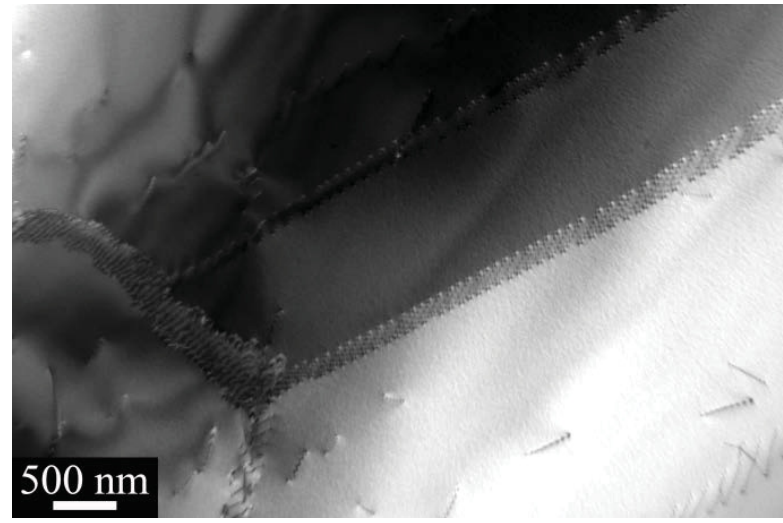

(b)

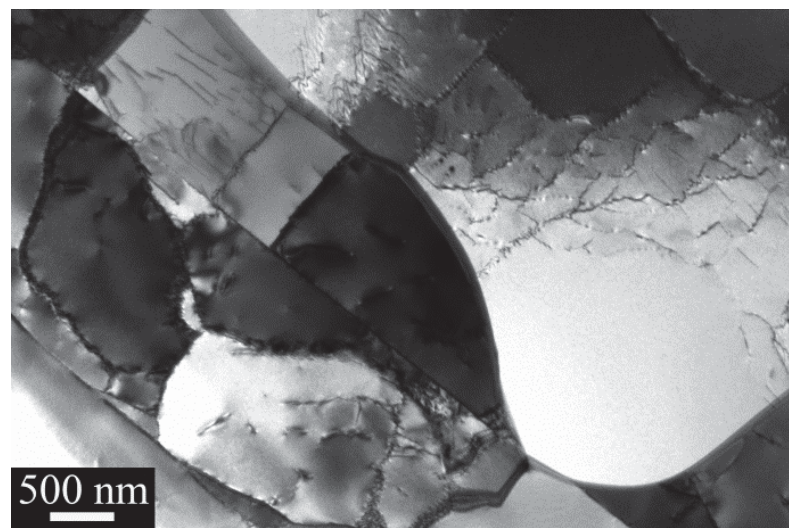

(d)

Figure 6. TEM images of specimens cycled at $1.0 \%$ total strain (a) and $0.3 \%$ total strain (b) in fatigue at $950^{\circ} \mathrm{C}$ showing a cellular structure and planar deformation bands and annealing twins. A creep-fatigue specimen cycled at $950^{\circ} \mathrm{C}$ with a $600 \mathrm{sec}$ hold at a $1.0 \%$ total strain (c) and a $0.3 \%$ total strain (d) showing a subgrain structure with boundaries comprised of ordered dislocation networks and a lower dislocation density in the cell interiors.

The creep-fatigue substructure at failure consists of subgrains with even fewer mobile dislocations within the subgrain interiors along with well-organized boundaries of arrays or networks of dislocations, as shown in Figures 6(c) and 6(d), respectively. The size of the subgrains can vary even within a single grain, although they are generally on the order of $1 \mu \mathrm{m}$ along any major dimensional axis. The dislocations forming the subgrain boundaries are arranged into distinct and well-organized networks; the spacing between dislocations visible in a single $g$-vector is on the order of $5-10 \mathrm{~nm}$ for the $0.3 \%$ and the $1.0 \%$ total strain range in the $600 \mathrm{~s}$ hold condition. TEM-based quantification of the $\alpha / \beta$ tilt offset between adjacent zone axes was employed to evaluate misorientation between subgrains, and indicates approximately $1-2^{\circ}$ of rotation between adjacent boundaries in specimens at both strain ranges. The boundary dislocations contain numerous jogs and kinks, indicative of considerable dislocation interaction prior to or during their arrangement into ordered networks. Figure 7 shows in more detail a commonly observed type of dislocation network that forms a subgrain boundary. The boundary dislocations rearrange into typical hexagonal networks consisting of $<110>\{111\}$-type dislocations as depicted through representative 2-beam (Figures 7[a] and [b]) and multiple-beam (Figure 7[c]) imaging conditions. The configuration of sense vectors of the individual dislocation types that comprise the well-ordered networks is illustrated schematically in Figure 7(d). 


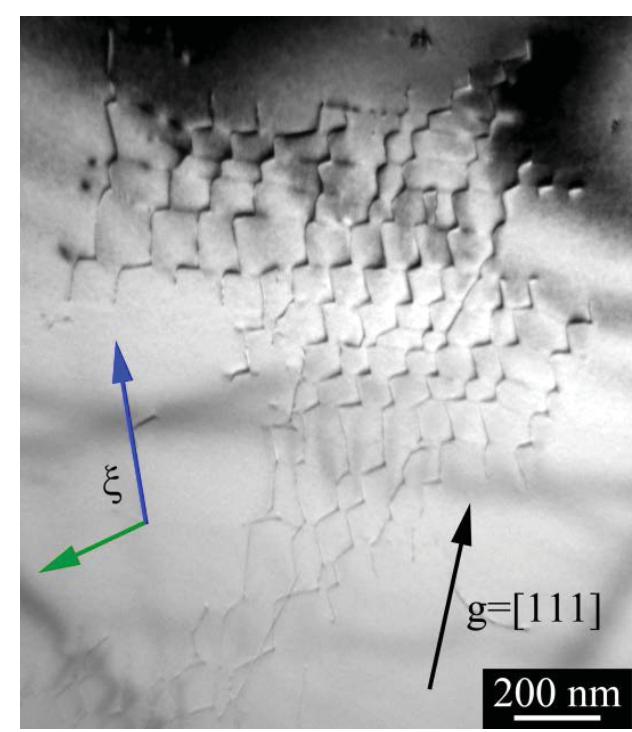

(a)

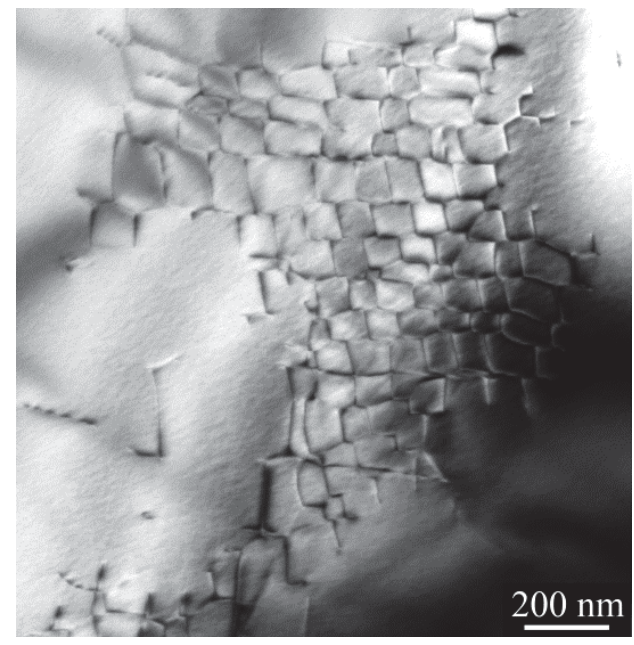

(c)

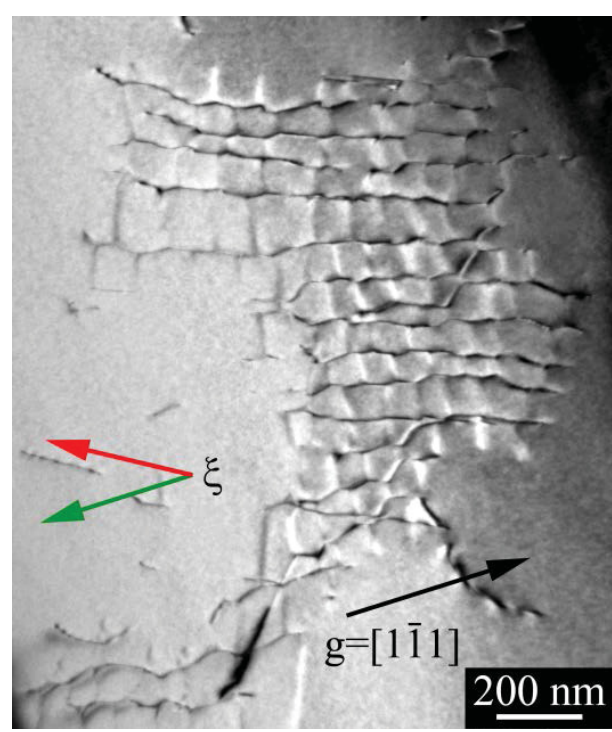

(b)

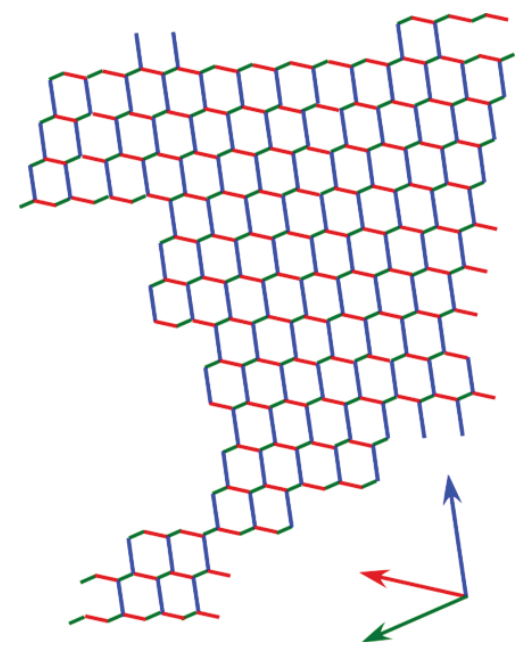

(d)

Figure 7. Low-energy hexagonal dislocation network in a tensile-hold creep-fatigue specimen tested at $950^{\circ} \mathrm{C}$, $0.3 \%$ total strain, and a $600 \mathrm{~s}$ hold time. Two of the 2-beam conditions that render one dislocation segment type invisible are shown in (a) and (b) along with a multi-beam imaging condition (c) to provide contrast for the entire network. A schematic (d) illustrates the individual sense vectors comprising the imaged hexagonal network. 


\subsection{Discussion of Creep-Fatigue Behavior at $950^{\circ} \mathrm{C}$}

A thorough comparison of the fatigue and creep-fatigue behavior at $950^{\circ} \mathrm{C}$ of Alloy 617 reveals a significant decrease in the number of cycles to failure with the addition of a hold time at peak tensile strain. This trend is fully consistent with literature data on the creep-fatigue behavior of nickel alloys $[2,3,7,8,9]$. Additionally, it is generally accepted that the fatigue behavior of most metals follows a Coffin-Manson type relationship, with the number of cycles to failure being a function of the inelastic strain $[10,11]$. Further attempts to simply modify the Coffin-Manson equation in order to account for frequency or hold time effects in a manner that is applicable to a wide range of alloys have not been widely applied. Interestingly, for Alloy 617, the relationship between the midlife inelastic strain range and the creep-fatigue life at the lower strain range $(0.3 \%$ total strain) follows this straightforward fatigue relationship regardless of the hold period location [12] or hold time duration (Figure 1[b]). This essentially indicates that the creep-fatigue behavior is dominated by the plastic response of the material and thereby must be controlled by microstructural features and deformation phenomena. This also suggests a relatively minor role of the environment on the accelerating crack propagation or failure than would otherwise be strongly suspected at high temperatures. The limited environmental role in the creep-fatigue behavior of Alloy 617 at $950^{\circ} \mathrm{C}$ at the $0.3 \%$ total strain range is further confirmed both by cycling with a zero-stress hold [12] and by the apparent saturation in creep-fatigue life with increasing hold times (Figure 1[a]). Previous work strongly supports these assertions, as it identifies a negligible influence of VHTR-based helium environment on the fatigue and creep-fatigue cycle life of Alloy 617 under otherwise similar test conditions [13]. The importance of this finding for reactor operating conditions cannot be overemphasized from a practical application standpoint, as an IHX material will likely be subjected to low strain range conditions for which the $0.3 \%$ total strain range is most representative [1]. This Coffin-Manson type behavior is not present at the higher strain ranges.

The decrease in fatigue life with the addition of a hold time is associated with a transition in the crack initiation and propagation mode from transgranular in continuous-cycle fatigue to intergranular when a hold time is incorporated. The switch in cracking mode is driven by the interior grain boundary cracking occurring as a result of the creep deformation in the tensile-hold period linking with the fatigue-driven surface cracks. At a finer scale, distinct dislocation subgrain structures develop during creep-fatigue deformation, but are not present following continuous low-cycle fatigue deformation. These substructures form initially by the tangling of dislocations into walls. Further cycling allows for dislocation climb, reorganization, and the integration of dislocations from the subgrain interiors along with the evolution into well-ordered hexagonal dislocation networks that form the subboundaries. The dislocation density within the subgrains also decreases with progressive cycling.

\section{4. $850^{\circ} \mathrm{C}$ FATIGUE AND CREEP-FATIGUE RESULTS}

\subsection{Cyclic Behavior}

The cyclic behavior at the $0.3 \%$ and $1.0 \%$ total strain ranges was also investigated at $850^{\circ} \mathrm{C}$ with hold times of up to $1800 \mathrm{~s}$ (30 minutes). Figure $8(\mathrm{a})$ and Table 3 show the number of cycles to failure at this temperature as a function of hold time. As was observed at $950^{\circ} \mathrm{C}$, the addition of a tensile hold time decreased the total number of cycles to failure relative to the continuous-cycle fatigue condition. A particularly dramatic effect occurred at the $0.3 \%$ total strain range, in which a decrease of nearly an order of magnitude in the number of cycles to failure was observed in creep-fatigue relative to continuous-cycle fatigue. The number of cycles to failure at the $0.3 \%$ total strain range decreased from approximately 10,000 cycles in fatigue to roughly 2000 cycles depending on the hold time duration. This degradation in life is more dramatic than at any strain range at $950^{\circ} \mathrm{C}$ or the $1.0 \%$ strain range at $850^{\circ} \mathrm{C}$. The number of cycles to creep-fatigue failure at the $1.0 \%$ strain range decreased by less than a factor of 2 relative to the continuous-cycle fatigue tests. In contrast to the creep-fatigue behavior at $950^{\circ} \mathrm{C}$, the duration of the hold time at $850^{\circ} \mathrm{C}$ appears to continue to degrade the cycle life at each of the strain ranges being evaluated, as is evident from Figure 8(a). At the present time, the compiled data set is not sufficient to accurately determine whether the number of cycles to failure saturates at longer hold durations. 
Table 3. Summary of the fatigue and creep-fatigue data at $850^{\circ} \mathrm{C}$.

\begin{tabular}{|c|c|c|c|c|c|c|c|c|c|c|c|c|c|c|c|}
\hline Specimen & $t_{\mathrm{h}}$ & $\Delta \varepsilon_{\mathrm{t}}$ & & & at Cycle 1 & & & & & Midlife & & & & & \multirow[b]{2}{*}{ Valid } \\
\hline \multirow[t]{2}{*}{ ID } & & & $\sigma_{\max }$ & $\sigma_{\min }$ & $\sigma_{\mathrm{h} \text {-start }}$ & $\sigma_{\text {h-end }}$ & $\Delta \varepsilon_{\text {in }}$ & $\sigma_{\max }$ & $\sigma_{\text {min }}$ & $\sigma_{\text {h-start }}$ & $\sigma_{\text {h-end }}$ & $\Delta \varepsilon_{\text {in }}$ & $\begin{array}{c}\text { Cycles } \\
\text { to } \\
\text { Initiation }\end{array}$ & $\begin{array}{c}\text { Cycles } \\
\text { to Failure }\end{array}$ & \\
\hline & (min) & $(\%)$ & (MPa) & $(\mathrm{MPa})$ & (MPa) & (MPa) & $(\%)$ & (MPa) & $(\mathrm{MPa})$ & (MPa) & $(\mathrm{MPa})$ & $(\%)$ & $\left(\mathrm{N}_{0}\right)$ & $\left(\mathrm{N}_{20}\right)$ & \\
\hline $43-6$ & 0 & 0.3 & 176.5 & -171.3 & & & 0.0777 & 192.9 & -191.5 & & & 0.0389 & 9900 & 10495 & $\mathrm{~T}$ \\
\hline $43-13$ & 0 & 0.3 & 181.0 & -174.3 & & & 0.1016 & 206.4 & -198.8 & & & 0.0509 & 8500 & 8904 & $\mathrm{Y}$ \\
\hline $43-22$ & 0 & 0.3 & 181.3 & -176.8 & & & 0.1006 & 200.1 & -203.4 & & & 0.0370 & 10000 & 10631 & $\mathrm{Y}$ \\
\hline $4-1-10$ & 3 & 0.3 & 181.0 & -198.6 & 180.1 & 68.3 & 0.1525 & 168.1 & -214.0 & 165.1 & 64.9 & 0.1154 & 1402 & 1944 & $\mathrm{Y}$ \\
\hline $4-1-12$ & 3 & 0.3 & 184.7 & -202.2 & 184.7 & 55.8 & 0.1567 & 169.1 & -218.3 & 178.0 & 65.4 & 0.1166 & 1954 & 2547 & $\mathrm{Y}$ \\
\hline $4-1-20$ & 10 & 0.3 & 178.7 & -198.8 & 150.4 & 41.0 & 0.1420 & 179.3 & -224.9 & 179.3 & 52.2 & 0.150 & 950 & 1475 & $\mathrm{~T}$ \\
\hline $4-1-22$ & 10 & 0.3 & 178.1 & -198.6 & 176.9 & 40.4 & 0.1720 & 174.3 & -221.5 & 171.0 & 46.1 & 0.1210 & 1300 & 1750 & $\mathrm{~T}$ \\
\hline $4-2-9$ & 10 & 0.3 & 166.7 & -199.4 & 161.1 & 37.3 & 0.1500 & 175.5 & -226.5 & 174.6 & 37.8 & 0.1360 & 1080 & 2104 & $\mathrm{Y}$ \\
\hline 4-7-1 & 30 & 0.3 & 174.3 & -199.0 & 172.8 & 31.2 & 0.2095 & 170.9 & -216.3 & 169.2 & 33.1 & 0.1369 & 790 & 1200 & $\mathrm{~T}$ \\
\hline $4-7-3$ & 30 & 0.3 & 175.5 & -194.4 & 174.9 & 43.5 & 0.1679 & 172.6 & -213.5 & 172.6 & 23.9 & 0.1568 & 880 & 1255 & $\mathrm{~T}$ \\
\hline 416-7 & 0 & 1.0 & 254.2 & -260.0 & & & 0.6733 & 269.2 & -270.5 & & & 0.6363 & 660 & 821 & $\mathrm{Y}$ \\
\hline 416-9 & 0 & 1.0 & 258.1 & -259.3 & & & 0.6895 & 271.6 & -274.8 & & & 0.6601 & 620 & 850 & $\mathrm{~T}$ \\
\hline 416-22 & 0 & 1.0 & 269.7 & -277.7 & & & 0.7233 & 269.1 & -275.3 & & & 0.6941 & 680 & 813 & $\mathrm{Y}$ \\
\hline $4-2-1$ & 3 & 1.0 & 217.6 & -266.2 & 216.9 & 37.4 & 0.8124 & 209.6 & -259.2 & 205.1 & 36.0 & 0.7989 & 258 & 544 & $\mathrm{Y}$ \\
\hline $4-2-4$ & 3 & 1.0 & 239.4 & -257.9 & 236.0 & 58.7 & 0.8003 & 225.1 & -244.5 & 220.6 & 50.7 & 0.7923 & 393 & 660 & $\mathrm{Y}$ \\
\hline $4-2-2$ & 10 & 1.0 & 223.4 & -276.8 & 220.9 & 28.2 & 0.8105 & $\begin{array}{l}206.8 \\
\end{array}$ & -263.2 & 204.9 & 25.3 & 0.7852 & 308 & 487 & $\mathrm{Y}$ \\
\hline $4-2-5$ & 10 & 1.0 & 235.4 & -258.0 & 234.8 & 42.6 & 0.8072 & 222.0 & -243.0 & 215.3 & 41.2 & 0.8021 & 388 & 548 & $\mathrm{~T}$ \\
\hline 4-2-7 & 30 & 1.0 & 242.3 & -264.3 & 240.6 & 31.7 & 0.8260 & 229.2 & -248.7 & 229.5 & 35.4 & 0.8101 & 185 & 371 & $\mathrm{Y}$ \\
\hline $4-2-8$ & 30 & 1.0 & 250.5 & -262.2 & 249.2 & 36.8 & 0.8190 & 215.1 & -240.5 & 210.4 & 30.2 & 0.7799 & 310 & 453 & $\mathrm{Y}$ \\
\hline
\end{tabular}

It was previously discussed that at $950^{\circ} \mathrm{C}$ and $0.3 \%$ total strain, the detriment in creep-fatigue cycle life is directly related to the increase in the midlife inelastic strain range when a tensile hold is added to the continuous-cycle waveform. The Coffin-Manson plot in Figure $1(\mathrm{~b})$ is shown with the addition of the $850^{\circ} \mathrm{C}$ fatigue and creep-fatigue data in Figure $8(\mathrm{~b})$. The $850^{\circ} \mathrm{C}$ fatigue and creep-fatigue data points fall to the left of the Coffin-Manson line that was fit to the $950^{\circ} \mathrm{C}$ fatigue data, which strongly suggests that the $850^{\circ} \mathrm{C}$ creep-fatigue failure mechanisms differ from those dominating at the $0.3 \%$ strain range at $950^{\circ} \mathrm{C}$. Despite not being illustrated graphically due to the lack of data at an intermediate strain range, the $850^{\circ} \mathrm{C}$ fatigue data may also follow a Coffin-Manson relationship. If it follows the trend established by the other data at $850^{\circ} \mathrm{C}$, this relationship would clearly differ from that of the higher temperature fatigue data.

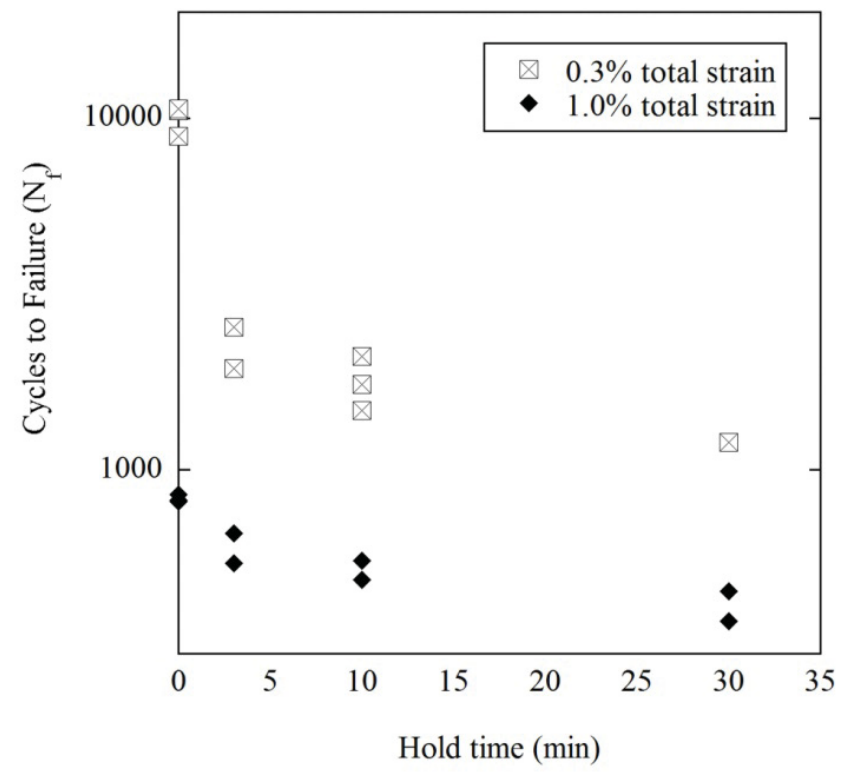

(a)

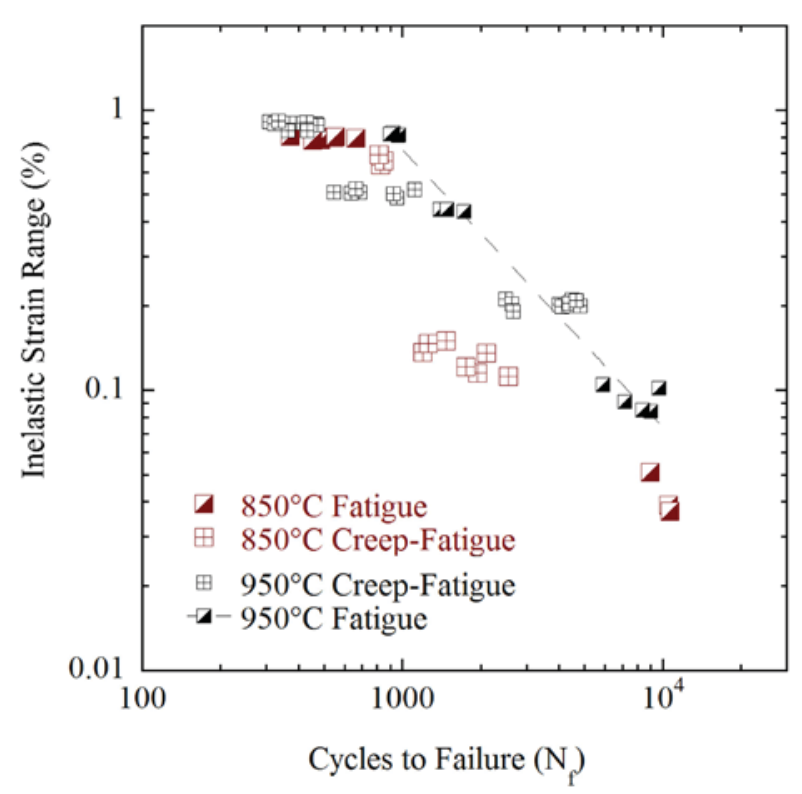

(b)

Figure 8. Plot of the total strain range (a) and inelastic strain range (b) as a function of cycles to failure for Alloy 617 in fatigue and creep-fatigue at $850^{\circ} \mathrm{C}$ at three strain ranges, $0.3 \%$ and $1.0 \%$, for hold times of up to 30 minutes. The plot in (b) also includes the $950^{\circ} \mathrm{C}$ fatigue and creep-fatigue data for comparison and the dashed line represents the Coffin-Manson relationship for the $950^{\circ} \mathrm{C}$ fatigue data. 
In fatigue, a small amount of cyclic hardening is observed at the $0.3 \%$ strain range (Figure 9[a]), whereas at the $1.0 \%$ strain range (Figure 9[b]) the peak stress versus cycle plot exhibits a relatively constant stress. Higher stresses are achieved at the $1.0 \%$ strain range than at the $0.3 \%$ total strain, which is reflective of the additional hardening occurring at the lower temperature [14]. In creep-fatigue testing, slight cyclic hardening that closely resembles the fatigue behavior is observed at the $0.3 \%$ strain range. The creep-fatigue tests at $1.0 \%$ strain with 3 minute and 10 minute hold times also nearly follow the behavior of the associated $1.0 \%$ fatigue test, although the 30 minute hold condition exhibits a significantly larger degree of cyclic softening.

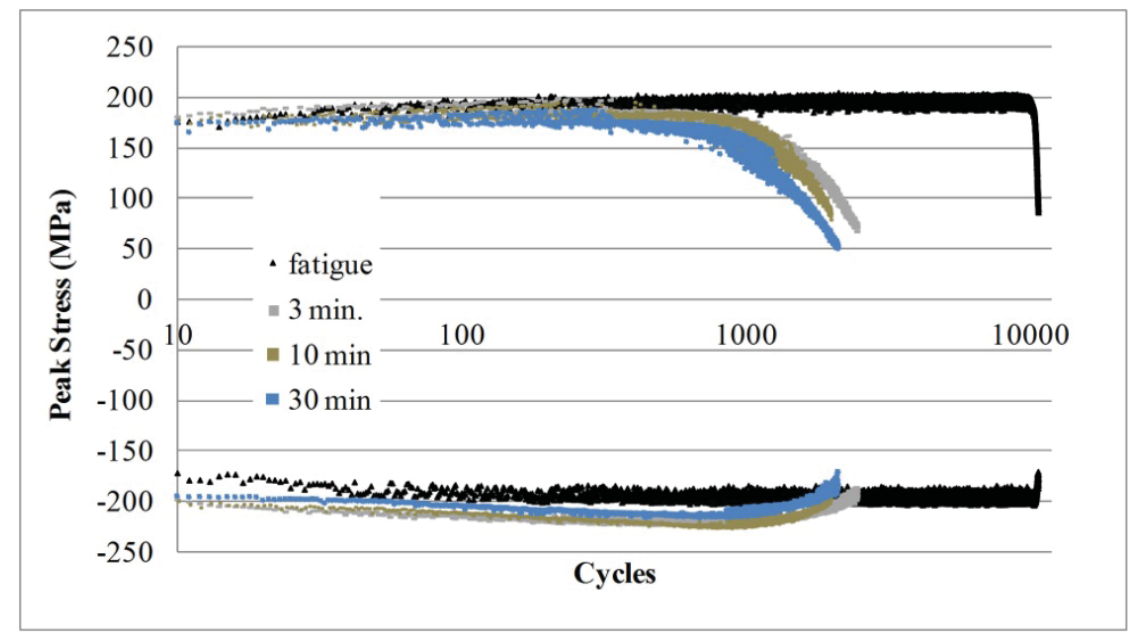

(a)

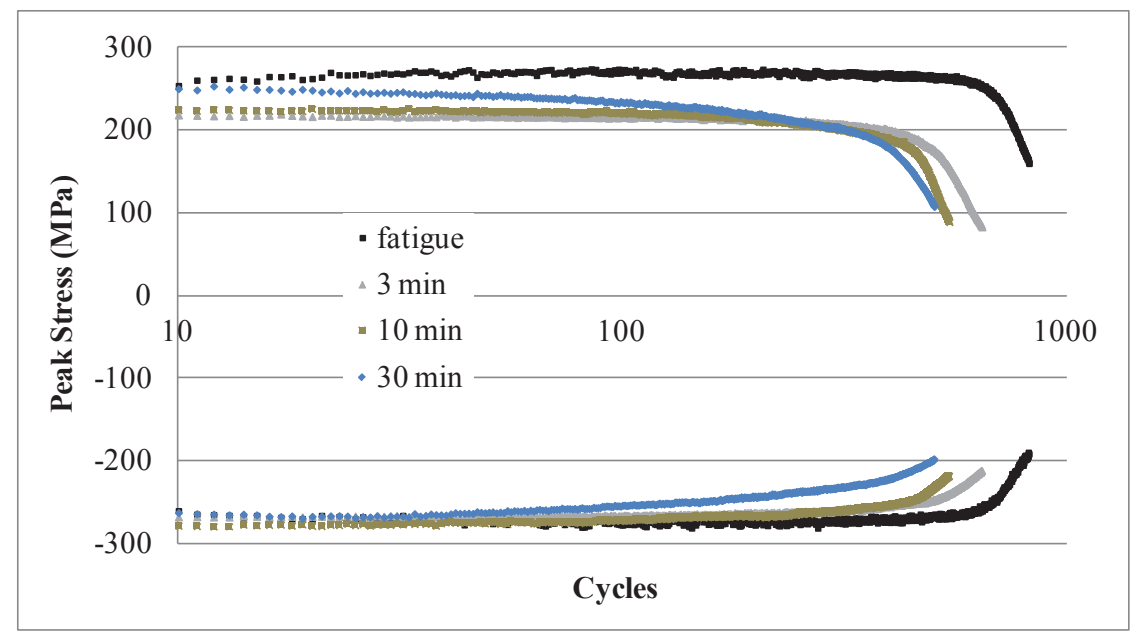

(b)

Figure 9. Peak stresses as a function of cycle for a typical fatigue and creep-fatigue tests at $850^{\circ} \mathrm{C}$ and $0.3 \%$ total strain (a) and a 1.0\% total strain (b).

Fatigue and creep-fatigue hysteresis loops at both the tenth cycle and midlife cycle are shown for the $0.3 \%$ total strain range in Figure 10. At the 10th cycle (Figure 10[a]), increasing durations of the strain-controlled hold result in a lower "relaxed" stresses, or stress at the end of the strain-controlled hold. The lower relaxed stresses result in increasingly wider hysteresis loops or larger inelastic strains. This increased width is evident from the segment of the hysteresis loop following the tensile hold, but is less clear on the compressive side of the loop due to the strain overshoot commonly observed early in cycling. This overshoot of the target strain values is illustrated through a plot of the peak tensile and compressive strain values shown in Figure 11 for a 3 minute hold creep-fatigue specimen. The peak strains frequently exceed the target command strain on both the compressive and tensile side of the waveform during cycling as a result of the onset of dynamic strain aging (DSA) [15], a phemomenon evident from the distinct serrations in the plotted loops. The absence of the serrations in the $0.3 \%$ 
hysteresis loops is a function of the low strain range; DSA begins to occur at some minimum plastic strain that happens to closely correlate with the target strain for this test conditions. The overshoot in strain at the point of strain reversal is thus a result of a serrated yielding event occurring at the peak tensile or compressive strain. More detail on this specific behavior is available in other studies for Alloy 617 and Alloy 230 at $800^{\circ} \mathrm{C} \mathrm{[15].} \mathrm{The}$ serrated response attributable to DSA is also observed in the $1.0 \%$ total strain hysteresis loops shown in Figure 12.

An interesting feature of the $0.3 \%$ total strain hysteresis loops present by the midlife cycle is the absence of plastic behavior during the loading in tension. A large plastic region is observed in both the tensile and compressive side of the hysteresis loop at the 10th cycle but by midlife the loops have evolved to only exhibit a significant plastic region in the compressive side of the cycle. This "shifting" of the hysteresis loop does not occur at the $1.0 \%$ total strain range (Figure 12). Also absent at the $1.0 \%$ total strain range is the decreasing relaxed stress values with increasing tensile hold time; the relaxed stresses are approximately the same for each of the three different hold times.

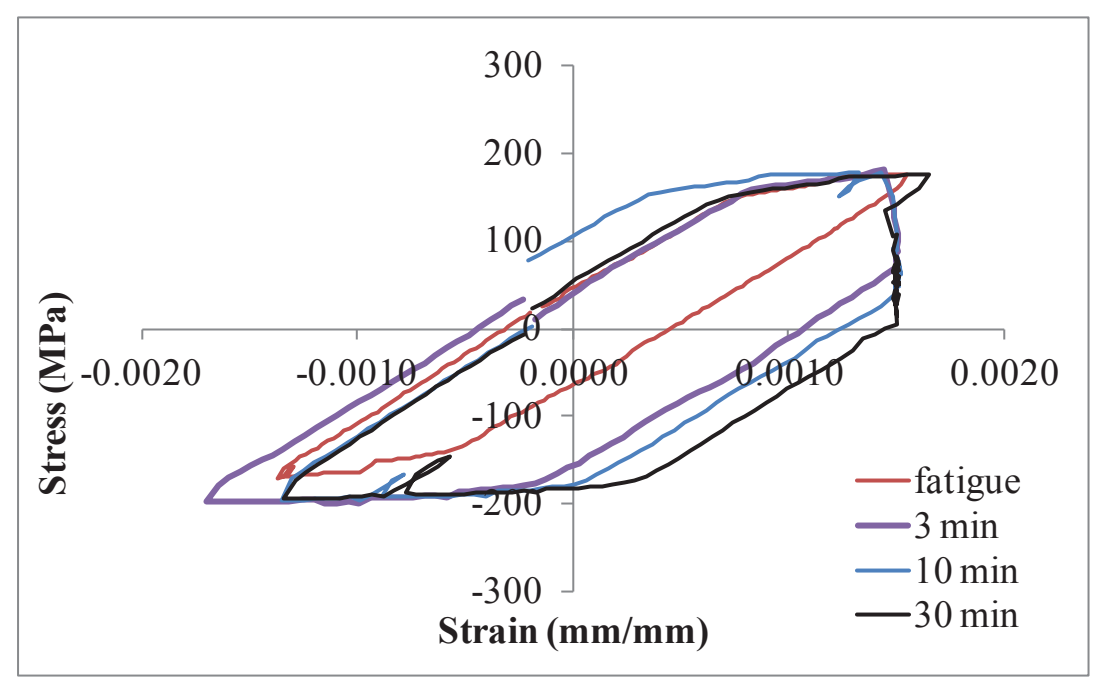

(a)

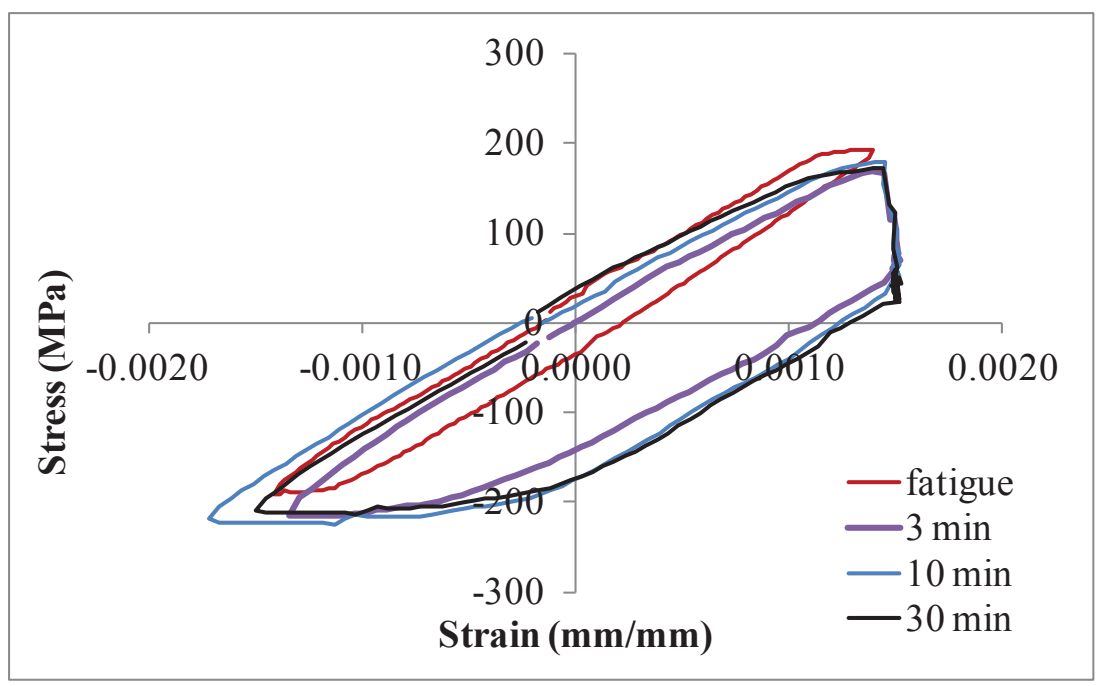

(b)

Figure 10. Tenth cycle (a) and a midlife cycle (b) hysteresis loops from a typical fatigue and creep-fatigue tests at $850^{\circ} \mathrm{C}$ and $0.3 \%$ total strain. 


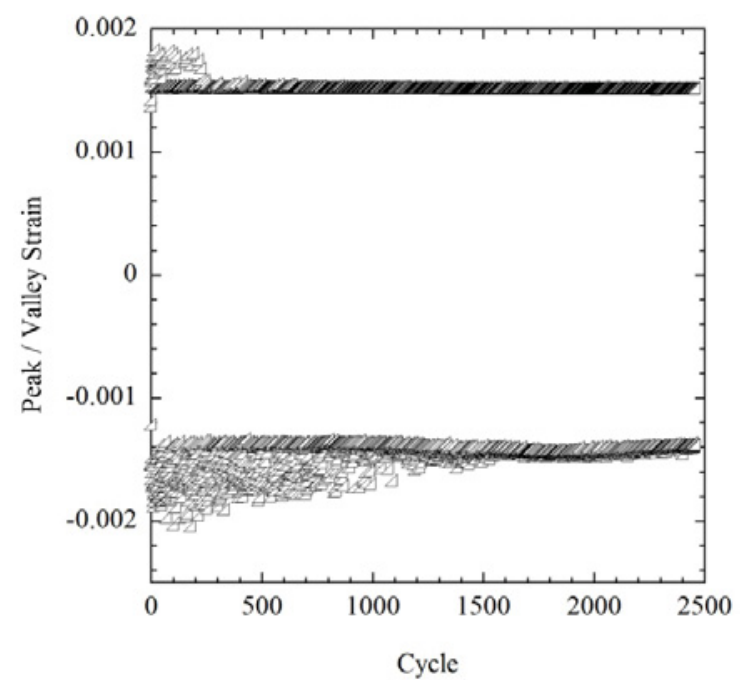

Figure 11. Plot of the peak and valley strain values from a 3 minute hold creep-fatigue test at the $0.3 \%$ total strain range and $850^{\circ} \mathrm{C}$.
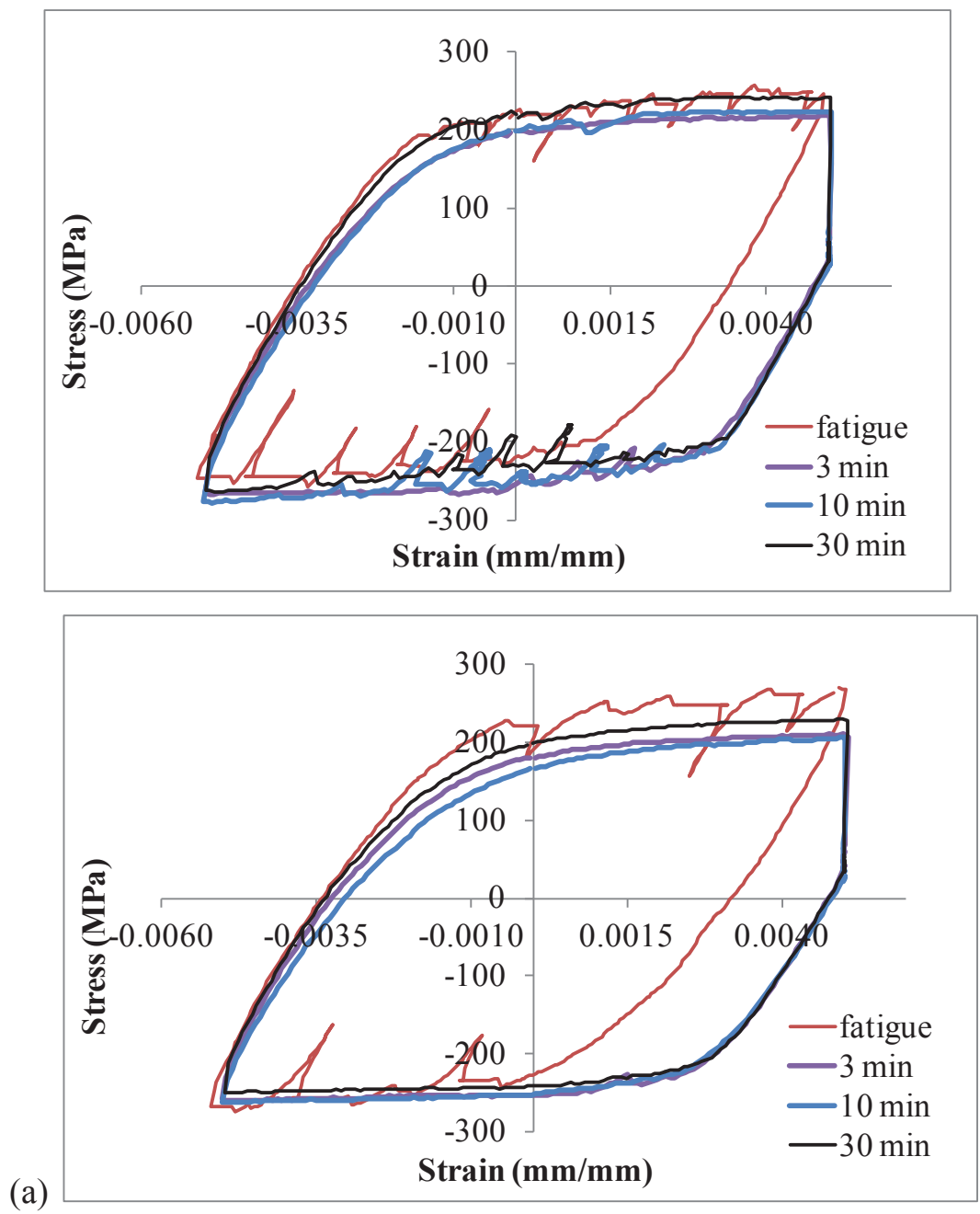

(b)

Figure 12. Tenth cycle (a) and a midlife cycle (b) hysteresis loops from a typical fatigue and creep-fatigue tests at $850^{\circ} \mathrm{C}$ and $1.0 \%$ total strain. 
The stress relaxation curves are shown as a function of time for both strain ranges at $850^{\circ} \mathrm{C}$ in Figure 13 . The initial relaxation is rapid, and at the $0.3 \%$ strain range the stresses continue to relax throughout the duration of the strain-controlled hold resulting in decreasing relaxed stresses. The trend is less clear at the higher strain range, as a longer hold time would be expected to result in a lower final value of relaxed stress. Either way, the relaxed stresses following the hold period are greater in magnitude than those observed for the $950^{\circ} \mathrm{C}$ creep-fatigue specimens.

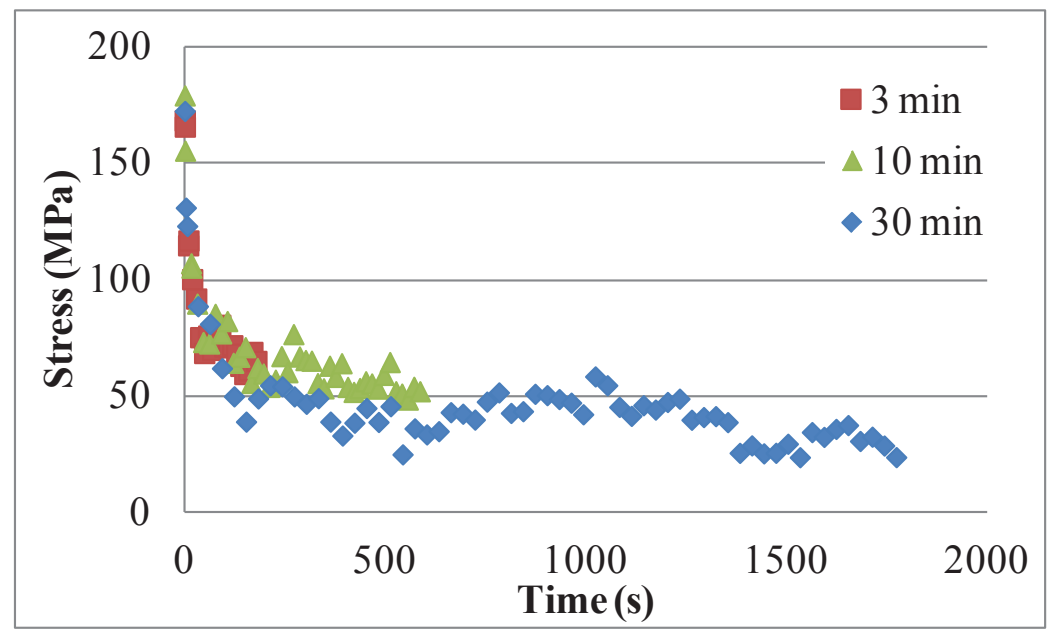

(a)

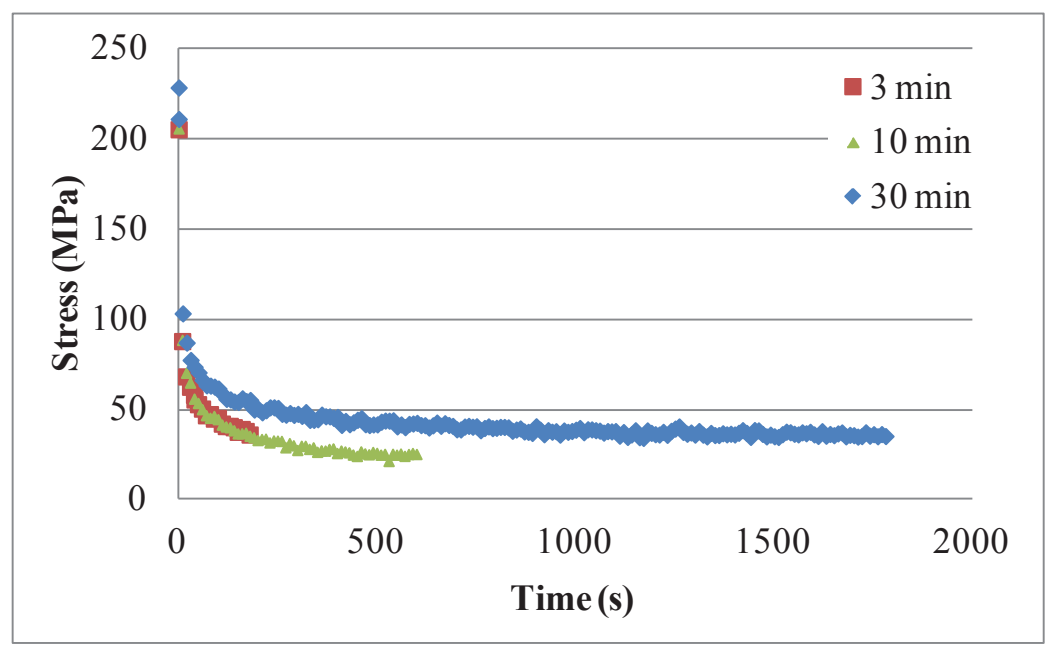

(b)

Figure 13. Typical stress relaxation curves from a midlife cycle of creep-fatigue tests at $850^{\circ} \mathrm{C}$ and $0.3 \%$ total strain (a) and $1.0 \%$ total strain (b).

\subsection{Microstructural Evolution During Cyclic Deformation}

The deformed microstructures developed during continuous-cycle and creep-fatigue cycling at $850^{\circ} \mathrm{C}$ follow a relatively predictable trend given the corresponding cycle lifetimes. Recall that the $0.3 \%$ total strain range exhibited a large decrease in the number of cycles to failure with the addition of a tensile hold time. The cycles to failure decreased only slightly as the hold time was increased from 3 minutes to 10 minutes to 30 minutes. At this strain range, continuous-cycle fatigue deformation induced the primary transgranular surface cracking shown in Figure 14(a). There was no evidence of secondary surface cracking or intergranular cracking along grain boundaries in the specimen interior. In contrast, many secondary surface cracks are evident following creep-fatigue deformation with a character that is primarily intergranular in the 3 minute and 10 minute hold specimens. The cracking mode of some of the longer secondary surface cracks had transgranular components near 
the crack tip. After a 30 minute hold, the creep-fatigue specimen exhibited both intergranular primary cracking, as illustrated in Figure 14(b), and secondary surface cracking.

The progression of the cracking mode from transgranular to intergranular with increasing hold time, along with the associated decrease in cycle life, corresponds with an increasing amount of interior grain boundary cracks at the $0.3 \%$ strain range. As at $950^{\circ} \mathrm{C}$, intergranular cracks were present throughout the specimens' interiors on select grain boundaries along a favorable component tending to be more perpendicular to the stress axis. As was done in a comprehensive manner in the specimens tested at $950^{\circ} \mathrm{C}$, the interior grain boundary cracking throughout the gage section was imaged and quantified. Somewhat surprisingly, no interior grain boundary cracks were present in the 3 minute hold $0.3 \%$ strain range creep-fatigue specimen, although they were prominent in the specimens subjected to longer hold times. The cracking modes and presence of interior grain boundary cracking is summarized in Table 4 and the interior grain boundary cracking is shown for a 10 minute hold time specimen in Figure 15. The amount of grain boundary cracking in selected hold time specimens has been quantified and is shown graphically in Figure 16. Comprehensive characterization revealed that the number of interior grain boundary cracks and the total cracked grain boundary length increased by over a factor of two in the 30 minute hold time specimen relative to the 10 minute hold time specimen.

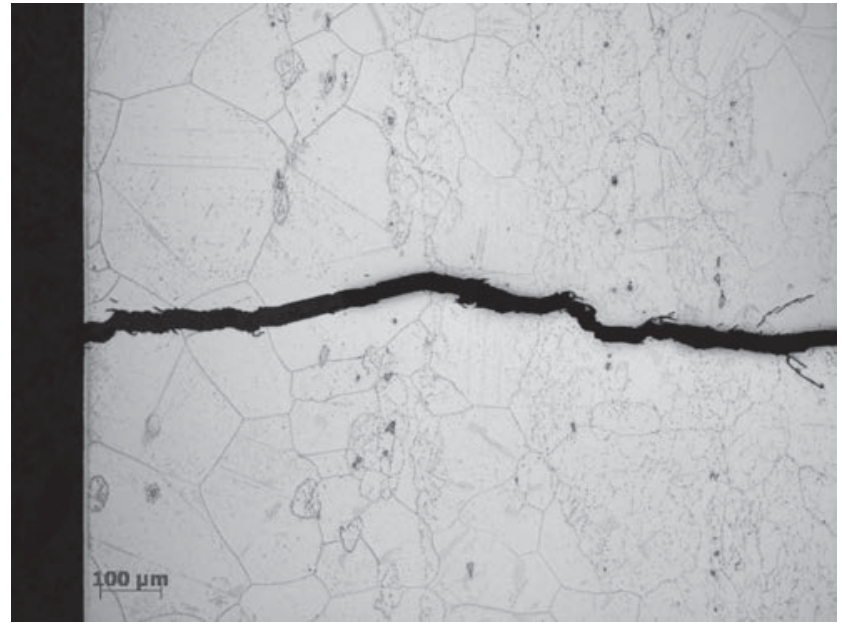

(a)

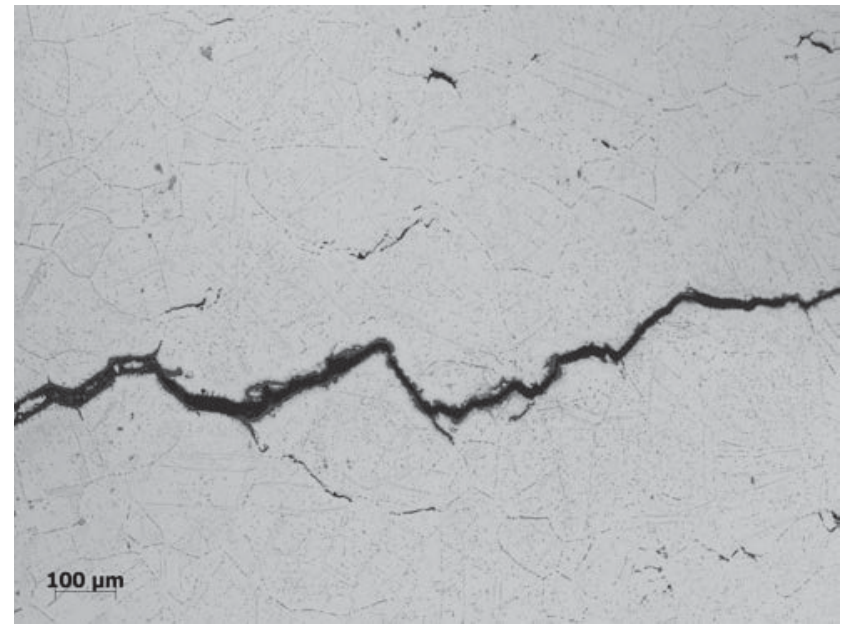

(b)

Figure 14. Transgranular surface cracking in a $0.3 \%$ total strain fatigue specimen cycled at $850^{\circ} \mathrm{C}$ (a). Intergranular surface cracking in a $0.3 \%$ total strain creep-fatigue specimen with a 30 minute tensile hold also cycled at $850^{\circ} \mathrm{C}(\mathrm{b})$. The stress axis is vertical and in the plane of the page.

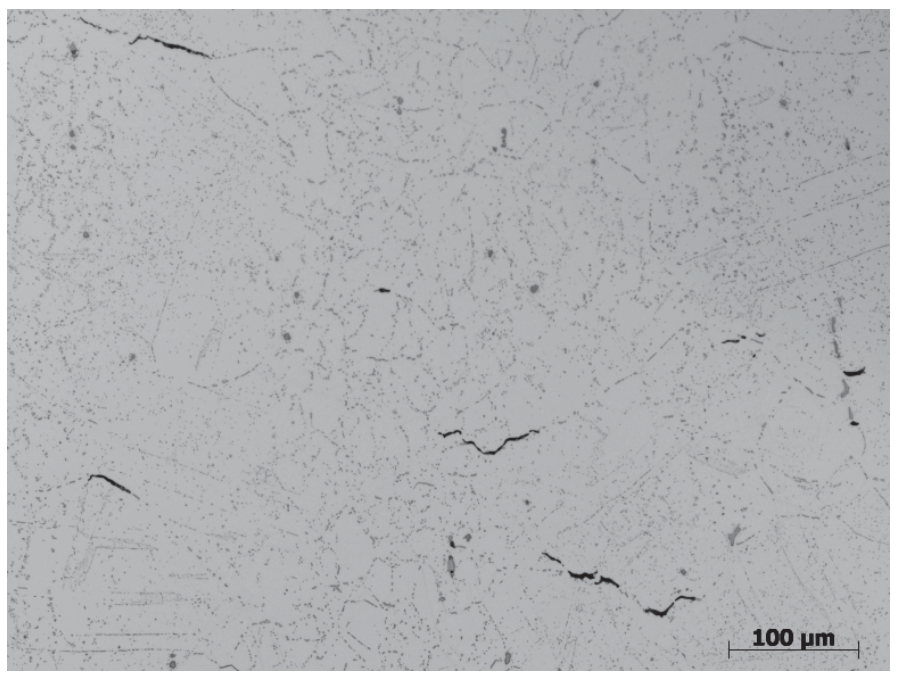

Figure 15. Internal grain boundary cracking (separation) in a specimen tested in creep-fatigue at $0.3 \%$ total strain and a 10 minute hold time at $850^{\circ} \mathrm{C}$. The stress axis is vertical and in the plane of the page. 
Table 4. Cracking modes in fatigue and creep-fatigue specimens tested at $850^{\circ} \mathrm{C}$. It was not possible to determine the primary surface cracking mode from the sectioned specimen cycled at $0.3 \%$ total strain with a 3 minute hold.

\begin{tabular}{|c|c|c|c|}
\hline & Primary cracking mode & Secondary cracking mode & Interior grain boundary cracking \\
\hline \multicolumn{4}{|c|}{$0.3 \%$ total strain } \\
\hline fatigue & Trans granular & None & No \\
\hline $3 \mathrm{~min}$ & & Primarily Intergranular & No \\
\hline $10 \mathrm{~min}$ & Mixed & Primarily Intergranular & Yes \\
\hline $30 \mathrm{~min}$ & Intergranular & Intergranular & Yes \\
\hline \multicolumn{4}{|c|}{$1.0 \%$ total strain } \\
\hline fatigue & Trans granular & Transgranular & No \\
\hline $3 \mathrm{~min}$ & Trans granular & Transgranular & Yes \\
\hline $10 \mathrm{~min}$ & Transgranular & Transgranular & Yes \\
\hline $30 \mathrm{~min}$ & Trans granular & Both & Yes \\
\hline
\end{tabular}

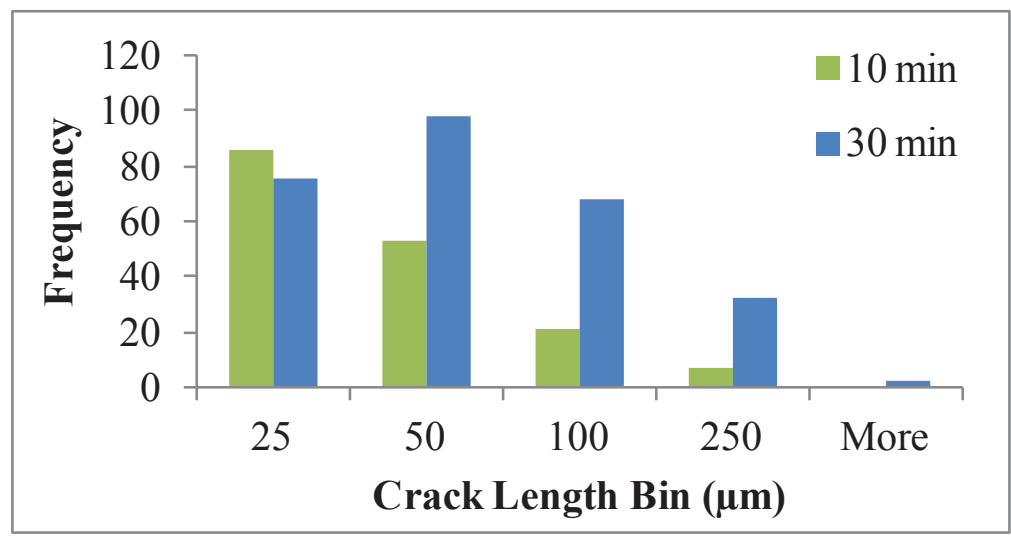

(a)

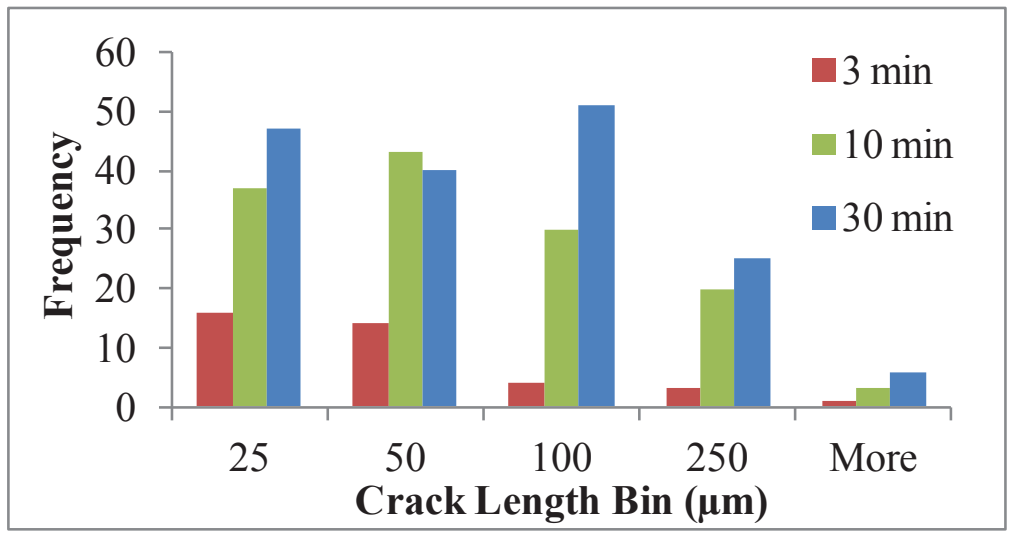

(b)

Figure 16. Length of individual internal grain boundary cracks in the gage section of specimens tested in creep-fatigue at $0.3 \%$ total strain (a) and $1.0 \%$ total strain (b) at $850^{\circ} \mathrm{C}$ for various hold times.

At the $1.0 \%$ total strain range, the total length and number of interior grain boundary cracks also increased with increasing duration of the tensile hold time and this is illustrated quantitatively in Figure 16. Despite the presence of interior grain boundary cracking, the mode of surface crack propagation was transgranular at $1.0 \%$ total strain regardless of hold time duration. A primary crack is shown in Figure 17 for the 3 minute hold 
condition. As expected, the cracking mode was also transgranular in fatigue. The relatively small decrease in the number of cycles to failure in creep-fatigue relative to the fatigue condition is consistent with the absence of intergranular cracking during creep-fatigue deformation.

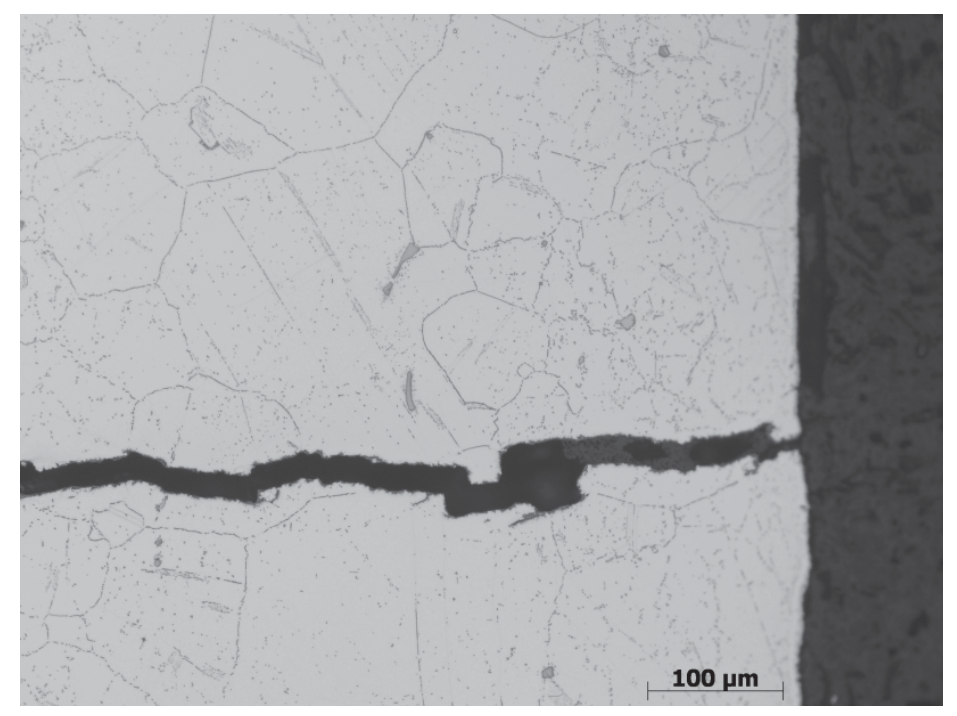

Figure 17. A primary crack propagating in a transgranular manner in a specimen tested in creep-fatigue at $850^{\circ} \mathrm{C}$ and a $1.0 \%$ total strain with a 3 minute hold time. The stress axis is vertical and in the plane of the page.

\section{SUMMARY}

The numbers of cycles to failure observed for fatigue at the $0.3 \%$ strain range were similar at 850 and $950^{\circ} \mathrm{C}$. A significant detriment in cycle life was observed when a hold time was added at peak tensile strain. The magnitude of this effect was greatest at the lowest strain range $(0.3 \%$ total strain) and less substantial at the higher strain ranges. Increases in the tensile hold duration beyond the initial value tested (3 minutes) were not increasingly detrimental to the creep-fatigue resistance at $950^{\circ} \mathrm{C}$, but continued to degrade the lifetimes at $850^{\circ} \mathrm{C}$. Contradictory to what might be expected, the number of cycles to failure for creep-fatigue at the $0.3 \%$ strain range condition was actually lower at $850^{\circ} \mathrm{C}$ than at $950^{\circ} \mathrm{C}$ for all of the hold times investigated.

The fact that the detriment in creep-fatigue cycle lifetimes saturates at a short hold time at $950^{\circ} \mathrm{C}$ is related to the rapid stress relaxation and low value of the relaxed stress in the strain-controlled hold along with the resulting microstructural features that contribute to the cyclic response. At $850^{\circ} \mathrm{C}$, the stress relaxation is more gradual and continues throughout the duration of the tensile hold, resulting in higher relaxed stresses that are consistent with the steadily decreasing cycle life at longer hold time conditions.

The microstructural evolution during creep-fatigue deformation also directly correlated with the stress relaxation behavior. Creep deformation induced during the hold period resulted in grain boundary cracking in the specimen interior along grain boundaries aligned on planes more perpendicular to the stress axis. At $950^{\circ} \mathrm{C}$, there was no difference in the interior grain boundary cracking observed for various hold times, which is consistent with the stresses relaxing to a low value early during the strain-controlled hold. At $850^{\circ} \mathrm{C}$, the amount of interior cracking is more directly related to the hold time.

Oxidized cracks were present at the specimen surface in all of the deformed specimens. Primary surface cracks propagated in a transgranular manner in fatigue at both temperatures and all strain ranges. The primary surface cracks formed during creep-fatigue deformation at $950^{\circ} \mathrm{C}$ were intergranular for all of the hold times investigated. In contrast, at the $0.3 \%$ strain range the primary surface cracks observed in $850^{\circ} \mathrm{C}$ creep-fatigue specimens were initially mixed in character except in specimens subjected to longest hold times, in which case intergranular cracking was predominant. Creep-fatigue cycling at $850^{\circ} \mathrm{C}$ at a $1.0 \%$ total strain range resulted in transgranular surface cracking. 


\section{REFERENCES}

[1] J.K. Wright, R.N. Wright, S. Sham, "Next generation nuclear plant steam generator and intermediate heat exchanger materials research and development plan," INL Report PLN-2804 (2010).

[2] K.B.S. Rao, H.P. Meurer, H. Schuster, "Creep-fatigue interaction of Inconel 617 at $950^{\circ} \mathrm{C}$ in simulated nuclear reactor helium," Mater. Sci. Eng. A Struct. Mater. 104 (1988) 37-51.

[3] P. Rodriguez, K.B.S. Rao, "Nucleation and growth of cracks and cavities under creep-fatigue interaction," Prog. Mater. Sci. 37 (1993) 403-480.

[4] R. Hales, "A quantitative metallographic assessment of structural degradation of type 316 stainless steel during creep-fatigue," Fatigue of Eng. Mater. Struct. 3 (1980) 339-356.

[5] W.J. Plumbridge, E.G. Ellison, "Low-cycle-fatigue behaviour of superalloy blade materials at elevated temperature," Mater. Sci. Technol. 3 (1987) 706-714.

[6] L.J. Carroll, C. Cabet, M.C. Carroll, R.N. Wright, "The development of microstructural damage during high temperature creep-fatigue of a nickel alloy," Inter. J. of Fatigue, 47 (2013) 115-125.

[7] T.C. Totemeier, H.B. Tian, “Creep-fatigue-environment interactions in Inconel 617," Mater. Sci. Eng. A Struct. Mater. 468 (2007) 81-87.

[8] S.Y. Lee, Y.L. Lu, et al., "Tensile-hold low-cycle-fatigue properties of solid-solution-strengthened superalloy at elevated temperature," Mater. Sci. Eng. A Struct. Mater. 504 (2009) 64-72.

[9] K.B.S. Rao, H. Schiffers, H. Schuster, H. "Nickel, Influence of time and temperature dependent processes on strain controlled low cycle fatigue behavior of alloy 617," Metall. Trans. A, 19 (1988) 359-371.

[10] L.F. Coffin, "Effect of frequency on cyclic strain and low cycle fatigue behavior of cast Udimet 500 at elevated temperature," Metall. Trans., 1972, vol. 3, pp. 1771-1788.

[11] L.F. Coffin, “A note on low cycle fatigue laws,” J. Mater., 1971, vol. 6, pp. 388-402.

[12] M.C. Carroll, L.J. Carroll, "Developing dislocation subgrain structures and cyclic softening during high temperature creep-fatigue of a nickel alloy," Metall. Trans. A, in press.

[13] L.J. Carroll, C. Cabet, and R.N. Wright: J. ASTM Int., 2011, no. 6, vol. 8, pp. 1-13.

[14] J.K. Wright, L.J. Carroll, J.A. Simpson, and R.N. Wright, "Low cycle fatigue of alloy 617 at 850 and $950^{\circ} \mathrm{C}$, ,J of Engin. Mater. Tech., in press.

[15] L.J. Carroll, W.R. Lloyd, J.A. Simpson, and R.N. Wright, "The Influence of Dynamic Strain Aging on Fatigue and Creep-Fatigue Characterization of Nickel-Base Solid Solution Strengthened Alloys," Mater. at High Temp. 27 no. 4, (2011) 313-323. 